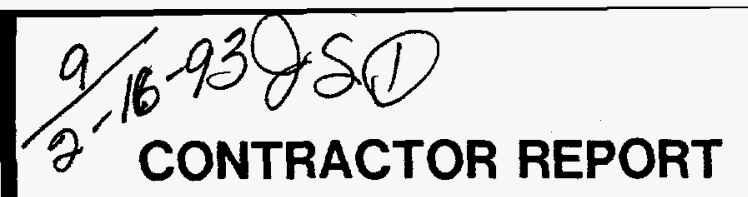

SAND92 - 7012

Unlimited Release

UC -274

\title{
Thin Silicon Solar Cells
}

R. B. Hall, C. Bacon, V. DiReda, D. H. Ford, A. E. Ingram, J. Cotter, T. Hughes-Lampros, J. A. Rand, T. R. Ruffins, A. M. Barnett

Astro Power, Inc.

Solar Park

Newark, DE 19716-2000

Prepared by Sandia National Laboratories Albuquerque, New Mexico 87185 and Livermore, California 94550 for the United States Department of Energy under Contract DE-AC04-76DP00789

Printed December 1992 
Issued by Sandia National Laboratories, operated for the United States Department of Energy by Sandia Corporation.

NOTICE: This report was prepared as an account of work sponsored by an agency of the United States Government. Neither the United States Government nor any agency thereof, nor any of their employees, nor any of their contractors, subcontractors, or their employees, makes any warranty, express or implied, or assumes any legal liability or responsibility for the accuracy, completeness, or usefulness of any information, apparatus, product, or process disclosed, or represents that its use would not infringe privately owned rights. Reference herein to any specific commercial product, process, or service by trade name, trademark, manufacturer, or otherwise, does not necessarily constitute or imply its endorsement, recommendation, or favoring by the United States Government, any agency thereof or any of their contractors or subcontractors. The views and opinions expressed herein do not necessarily state or reflect those of the United States Government, any agency thereof or any of their contractors.

Printed in the United States of America. This report has been reproduced directly from the best available copy.

Available to DOE and DOE contractors from

Office of Scientific and Technical Information

PO Box 62

Oak Ridge, TN 37831

Prices available from (615) 576-8401, FTS 626-8401

Available to the public from

National Technical Information Service

US Department of Commerce

5285 Port Royal Rd

Springfield, VA 22161

NTIS price codes

Printed copy: A03

Microfiche copy: A01 
Distribution

Category UC-274

SAND92-7012

Unlimited Release

Printed December 1992

\title{
THIN SILICON SOLAR CELLS
}

\author{
R.B. Hall, C. Bacon, V. DiReda, D.H. Ford \\ A.E. Ingram, J. Cotter, T. Hughes-Lampros \\ J.A. Rand, T.R. Ruffins, A.M. Bamett \\ AstroPower, Inc. \\ Solar Park
}

Newark, DE 19716-2000

Sandia Contract 69-2081

\begin{abstract}
The silicon-film design achieves high performance by using a thin silicon layer and incorporating light trapping. Optimally designed thin crystalline solar cells ( $<50$ microns thick) have performance advantages over conventional thick devices. The high-performance silicon-film design employs a metallurgical barrier between the low-cost substrate and the thin silicon layer. Light trapping properties of silicon-film on ceramic solar cells are presented and analyzed. Recent advances in process development are described here.
\end{abstract}




\section{Acknowledgments}

The authors gratefully acknowledge the valuable contributions of C.L. Kendall, J.C. Checchi, D.L. Brooks, and C.J. Colgan in the fabrication and processing of Silicon-Film ${ }^{\text {TM }}$ solar cells. Additionally, the authors thank Dr. Paul Basore of Sandia National Laboratories for providing comprehensive device measurements and analyses on laboratory-scale solar cells. 


\section{DISCLAIMER}

Portions of this document may be illegible electronic image products. Images are produced from the best available original document. 
Distribution

Category UC-274

SAND92-7012

Unlimited Release

Printed December 1992

\title{
THIN SILICON SOLAR CELLS
}

R.B. Hall, C. Bacon, V. DiReda, D.H. Ford

A.E. Ingram, J. Cotter, T. Hughes-Lampros

J.A. Rand, T.R. Ruffins, A.M. Barnett

AstroPower, Inc.

Solar Park

Newark, DE 19716-2000

Sandia Contract 69-2081

\begin{abstract}
The silicon-film design achieves high performance by using a thin silicon layer and incorporating light trapping. Optimally designed thin crystalline solar cells ( $<50$ microns thick) have performance advantages over conventional thick devices. The high-performance silicon-film design employs a metallurgical barrier between the low-cost substrate and the thin silicon layer. Light trapping properties of silicon-film on ceramic solar cells are presented and analyzed. Recent advances in process development are described here.
\end{abstract}




\section{Acknowledgment}

The authors would like to acknowledge the valuable contributions of Dr. Paul A. Basore of Sandia National Laboratories for providing comprehensive device measurements and analyses on laboratory-scale solar cells, including detailed modeling of light trapping properties. The assistance of Dr. Kent Schubert, also of Sandia National Laboratories, in the chemical analysis work is appreciated. 


\section{Table of Contents}

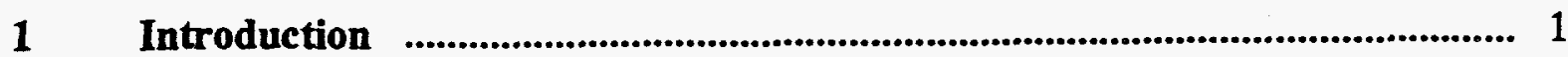

1.1 Silicon Film Product Families..................................................................... 1

1.2 Product II Device Structure ....................................................................... 3

1.3 Contract Objectives .................................................................................. 5

$1.4 \quad$ Summary of the Results............................................................................... 7

$2 \quad$ Device Modeling ................................................................................................. 9

3 Device Fabrication and Characterization ............................................................. 11

3.1 Conductive Ceramic Substrate ......................................................................... 11

3.2 Metallurgical Barrier Layer ......................................................................... 12

3.3 Light Trapping Properties.......................................................................... 14

3.3.1 Reflection Characteristics............................................................... 15

3.3.2 Quantum Efficiency Characteristics ............................................... 17

3.3.3 Light Trapping Analysis.................................................................. 19

3.3.3a Model for Effective Optical Path Length ....................... 19

3.3.3b Modeling for the Nearbandgap Case ............................. 23

3.3.3c Optical Effects on Light-Generated Current................... 26

3.3.3d Full-Spectrum Light-Trapping Effectiveness .................. 28

$4 \quad$ Solar Cell Device Results ................................................................................... 31

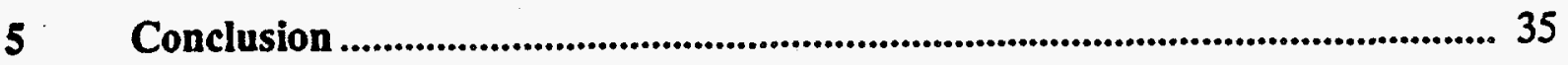

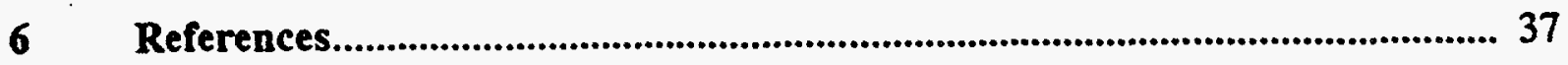




\section{List of Figures}

$1 \quad$ The Silicon-Film product families............................................................................ 3

2 Silicon-Film Product II ........................................................................................ 4

3 Predicted conversion efficiency (AM1.5G) as a function of base doping............... 10

$4 \quad$ Resistance measurements made on conductivity test structures ............................. 12

5 Cross section of Silicon-Film/metallurgical barrier/textured . ................................ 13

$6 \quad$ Normalized reflectivity of a Silicon-Film Product II structure................................. 15

7 Quantum efficiency of a silicon-on-ceramic structure .......................................... 17

8 Absorption length versus the inverse of the internal quantum efficiency ............. 18

$9 \quad Z(\lambda)$ for an AstroPower silicon-on-ceramic device .............................................. 22

10 Analysis of the nearbandgap spectral response ................................................... 25

11 Analysis of the nearbandgap spectral response ................................................. 25

12 Two theoretical cases of light-trapping structures ................................................ 26

13 The theoretical effective optical path length of the two devices ........................... 27

14 The photogeneration in silicon for the AM1.5G spectrum at $25^{\circ} \mathrm{C} \ldots \ldots . . . . . . . . . . . . . .29$

\section{List of Tables}

I Analysis of long wavelength reflectivity ................................................................ 16

II Device Processing Sequence ...................................................................................... 31

III Measured I-V Characteristics on $1.0 \mathrm{~cm}^{2}$ Silicon-Film Product II .......................... 32

IV Defect density measured on Silicon-Film Products................................................... 33 


\section{Introduction}

This report covers contract work for the period from July 1990 to October 1991.

The Silicon-Film process involves the deposition of a silicon layer on a conducting ceramic substrate. The ceramic has been coated with a reflective metallurgical barrier layer. The device structure has been designed to incorporate light trapping, and maximize the collection efficiency of photogenerated carriers. Obtaining back surface passivation at the Silicon-Film/metallurgical barrier is a key element in achieving high collection efficiency.

Device results for Product II structures on ceramic are presented that show the metallurgical barrier is up to $70 \%$ reflective, and significant levels of light trapping are present. The long wavelength spectral response and reflectance measurements are analyzed to estimate the level of light trapping achieved. Device efficiency has been limited to $6.6 \%$ by low minority carrier diffusion lengths. Significant levels of impurities have been detected in the silicon films and are believed to be causing the low diffusion lengths.

\subsection{Silicon-Film Product Families}

The development of the Silicon-Film process has generated a family of three products. They are pictured in Figure 1. Product I, being developed for production now, utilizes a 100$\mu \mathrm{m}$-thick active layer of silicon on a supporting substrate. There is no barrier layer between the active layer and the substrate, and no light trapping features are designed in the structure. A recent review of the production development of Product I reported an efficiency of 9.45\% [1].

Light trapping is incorporated into the Product II design shown in Figure 1. Product II differs from Product I by the presence of a metallurgical barrier layer, and by the reduction in thickness of the active silicon layer $(30 \mu \mathrm{m})$. There are performance and cost advantages to using a thin silicon structure as opposed to a thick conventional device. These advantages are 1) improved $V_{\infty}, 2$ ) reduced dependence on diffusion length (and therefore less stringent material 
purity and quality requirements), and 3) reduced cost through the use of less silicon. Light trapping must be incorporated into a thin device structure to assist in the absorption of the long wavelength light. Long wavelength light (wavelength range $0.9 \mu \mathrm{m}$ to $1.1 \mu \mathrm{m}$ ) is weakly absorbed in crystalline silicon. The design, modeling, and fabrication of the Product II device are reviewed in this work.

Product III utilizes the Silicon-Film process developed for Product II, therefore enjoying the performance and cost benefits of the thin silicon light trapping design. The active silicon layer is configured into a monolithically integrated, high-voltage structure. This structure allows all electrical contacting to be made on the back of the device, therefore simplifying module assembly. The high-voltage, low-current configurations possible with such a device minimize contact resistance problems and avoid front surface shadowing by current carrying metallic bus bars. The Product III design allows the use of the large ceramic substrates $(10 \mathrm{~cm} \mathrm{x} 60 \mathrm{~cm})[1]$ generated by the Silicon-Film process. 


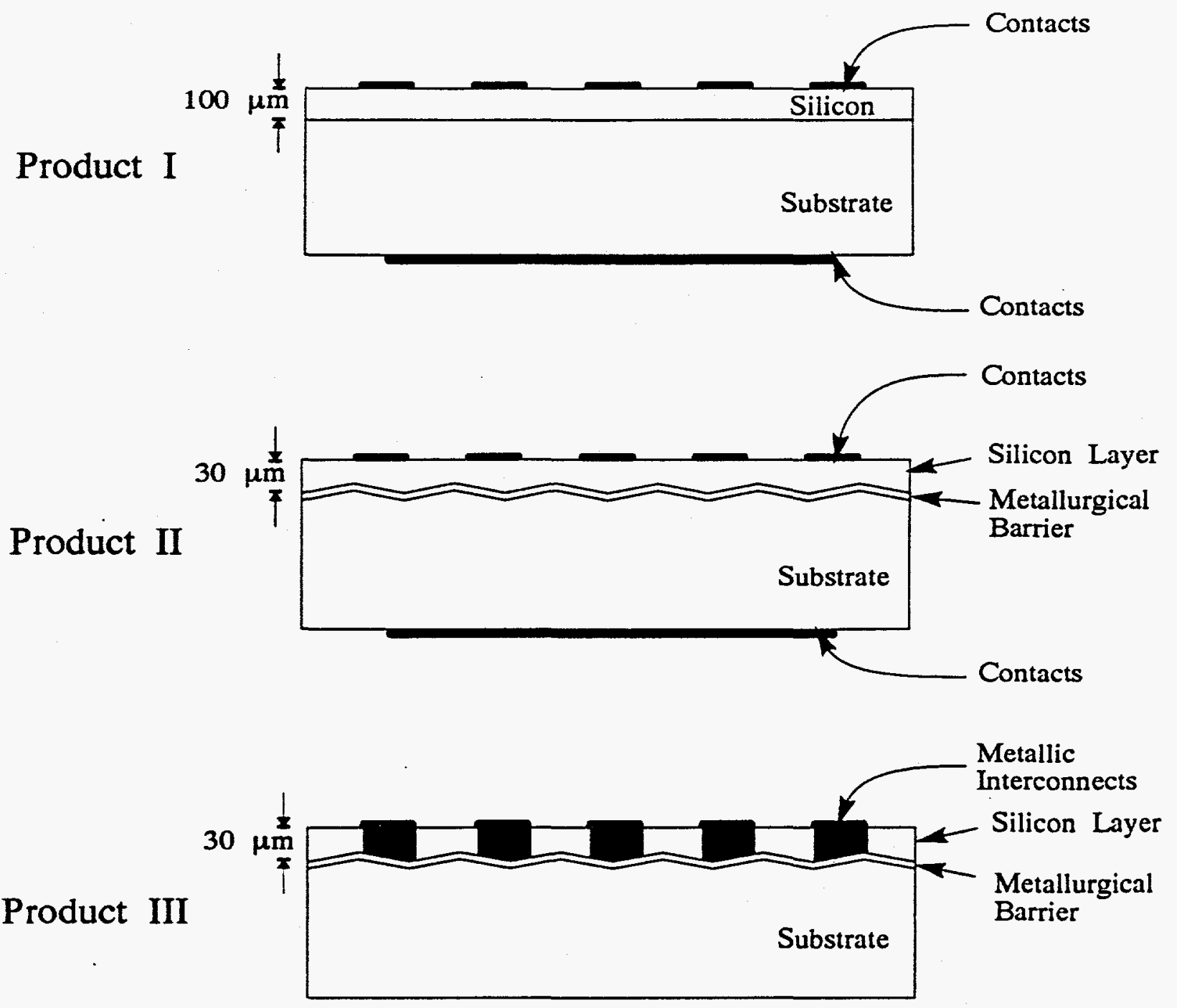

Figure 1. The Silicon-Film product families.

\subsection{Product II Device Structure}

Three Silicon-Film Product-II wafers are shown in Figure 2(a). The grain structure is long grains, millimeters in width and centimeters in length. A cross section is shown Figure 2 (b), where the grown crystalline silicon layer can be seen over a coarse ceramic substrate. The silicon layer pictured is approximately $70-\mu \mathrm{m}$ thick on a $600-\mu \mathrm{m}$-thick ceramic. The relatively large grain structure results in an aspect ratio exceeding 10 (ratio of the lateral grain dimension to the film thickness). 
(a)

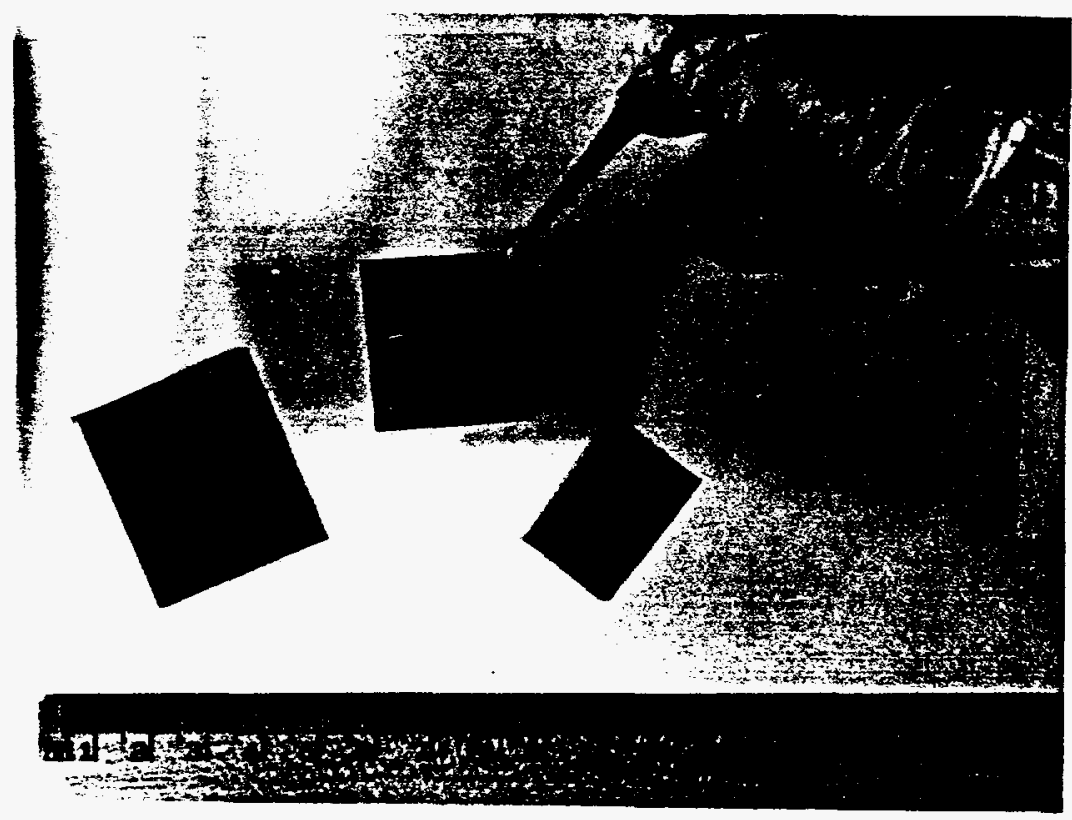

(b)

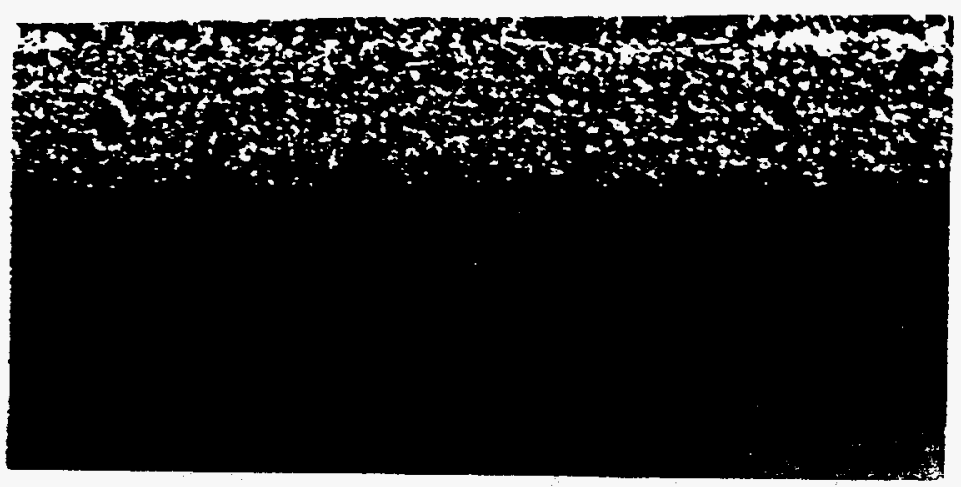

Figure 2. Silicon-Film Product II. Samples of Silicon-Film on ceramic are shown in (a).

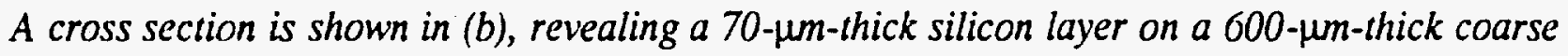
ceramic substrate. 
The ceramic is fabricated from low cost powdered materials, and is formed into its $10 \mathrm{~cm}$ $\times 10 \mathrm{~cm} \times 0.5 \mathrm{~mm}$ pieces, then heat treated to remove binders. Properties of the ceramic have been carefully chosen to maintain strength at the high silicon deposition temperatures, be expansion matched to silicon, and be electrically conductive.

The metallurgical barrier is deposited by production-based, low-cost processes. Interaction of the barrier and silicon active layer needs to result in a low-recombination surface to maximize efficiency [2]. High reflectivity and low recombination have been key design elements of the metallurgical barrier development.

The silicon active layer is deposited by the proprietary Silicon-Film technique. Films 50 to $500 \mu \mathrm{m}$ thick are grown. Aspect ratios (grain width to thickness ratio) exceed 10, with grain dimensions on the order of centimeters. Samples have been fabricated with and without metallurgical barrier layers using the same Silicon-Film process.

\subsection{Contract Objectives}

The primary objective has been to demonstrate that the high efficiency potential of crystalline silicon can be preserved while using an inexpensive growth process. Technology criteria were established by Sandia to guide the development effort, and are listed below.

1) The active silicon layer should have a thickness of at least $10 \mu \mathrm{m}$, with a $100 \mathrm{~cm}^{2}$ spatial thickness uniformity of $+/-25 \%$ or better. This lower thickness limit is dictated by considerations of product uniformity, defect tolerance, and absorption of the incident light.

2) The active silicon layer thickness should be less than the minority carrier diffusion length. This is necessary for collection of most of the photogenerated charge carriers. For the low-cost silicon, this limits the active carrier layer thickness to less than about $100 \mu \mathrm{m}$. For multicrystalline silicon, it also requires columnar grain structure with grain diameters at least four times the layer thickness.

3) The effective back-surface recombination velocity should be less than the layer's transit velocity, which is the ratio of the minority carrier diffusivity to the layer thickness. 
This is necessary for collection of most of the photogenerated charge carriers. For thin layers of silicon, this requires an effective rear-surface recombination velocity of less than about $10,000 \mathrm{~cm} / \mathrm{s}$.

4) The front surface, back surface, or both surfaces of the active silicon layer must be textured (non-planar) so that most of the light that enters the cell can be trapped within the silicon layer by total internal reflection, thus maximizing the photogeneration of carriers.

5) The optical reflectance of the internal rear surface of the active silicon layer must be sufficient to avoid parasitic absorption of light. The reflectance must be greater than about $80 \%$ for photon energies between $1.0 \mathrm{eV}$ and $1.5 \mathrm{eV}$ to avoid excessive optical losses.

6) Ohmic contacts to the back surface are required at spatial intervals comparable to those on the front surface, so that series resistance associated with conduction through the barrier layer is less than $0.5 \Omega \mathrm{cm}^{2}$.

7) The substrate, barrier and thin active silicon layer must be mechanically and chemically capable of being subjected to the high-temperature processing necessary to form the emitter junction.

8) The substrate, barrier, and thin active silicon layer satisfying the above specifications should be capable of being formed at a usable-area production rate of at least 5 $\mathrm{m}^{2} /$ week per $\$ 100,000$ of production equipment.

The total effort was delineated into 4 tasks addressing the development of the

1. Substrate,

2. Barrier-Layer,

3. Active Silicon Layer, and

4. Solar Cell Fabrication.

A set of solar cell devices and test structures were established as deliverables to assess product and process development. Solar cell deliverable goals were established to be a $1.0 \mathrm{~cm}^{2}$ device fabricated on a textured substrate, with a metallurgical barrier layer, silicon active layer, 
front and back metal contacts and an anti-reflection layer. The efficiency goal of the $1.0 \mathrm{~cm}^{2}$ device was $10 \%$ AM1.5. A $100 \mathrm{~cm}^{2}$ device deliverable was established without an efficiency target.

\subsection{Summary of the Results}

The capabilities of the Silicon-Film process was demonstrated with the fabrication of 100 $\mathrm{cm}^{2}$ structures, $1.0 \mathrm{~cm}^{2}$ solar cells, and various resistance and reflection test structures. A high conductivity ceramic fabrication process was developed. Many required elements of the process were developed, including: demonstration of light trapping properties, a Silicon-Film/ metallurgical barrier reflection of $70 \%$, fabrication of $100 \mathrm{~cm}^{2}$ conductive ceramic substrates, and demonstration of large grain silicon films $100 \mu \mathrm{m}$ thick over areas of $40 \mathrm{~cm}^{2}$.

A conductive ceramic was fabricated using low cost production based processes. $100 \mathrm{~cm}^{2}$ ceramics were tested at Sandia and found to have a resistivity of $10 \Omega \mathrm{cm}$, which would be sufficiently conductive for a one-sun device. Ohmic contact to the ceramic was demonstrated using standard screen printing techniques. A low contact resistance value was measured.

Silicon-on-ceramic structures were fabricated with and without intervening barrier layers. Thin silicon active layers with large columnar grains and thicknesses of 50 to $100 \mu \mathrm{m}$ were fabricated. This represents a grown layer thickness less than $1 / 2$ that demonstrated in earlier work. The achievement of grown layers less than $100 \mu \mathrm{m}$ thick required careful control of the metallurgical barrier properties. A set of thin grown layer structures with and without barriers were evaluated for internal silicon layer/barrier reflectance. The use of thick barrier layers resulted in barrier layer reflectivity approaching $80 \%$. Thin barrier layers, utilized to grown thin silicon film layers, resulted in reduced reflection $(<50 \%)$.

Light trapping properties have been measured and quantified in solar cell devices. With the help of models developed at Sandia, effective optical path lengths have been measured that indicate that light trapping properties of the randomly textured ceramic and reflectivity of thick barrier layers result in optical path lengths nine times the physical device thickness.

Solar cell devices were formed on silicon-on-ceramic structures formed with and without barrier layers. Overall efficiency remains limited by low short-circuit current. Low currents 
have been the result of low minority-carrier diffusion lengths. Metallic impurities have been found in both silicon feedstock and in grown films at levels that could significantly affect minority carrier properties. Overall AM1.5 conversion efficiency has been limited to $6.6 \%$ in a thin silicon-on-ceramic structure with a barrier present. 


\section{Device Modeling}

The effects of light trapping and back surface passivation are critical to realizing the high efficiency potential of the thin silicon films. The effects of these variables on overall device energy efficiency are shown in Figure 3. Values of back surface recombination of $10^{6} \mathrm{~cm} / \mathrm{sec}$ (unpassivated) and $10^{3} \mathrm{~cm} / \mathrm{sec}$ (passivated) are used. A single diode model (diode ideality factor = 1) has been used to compute open circuit voltages. This assumption eliminates any dependence of fill factor on changes in doping and diffusion length. A value of 0.82 for the fill factor has been used for all the efficiency calculations in Figure 3. A non-ideal relationship between doping and minority carrier lifetime has been used to determine the diffusion length dependence on doping. Lifetime values predicted for single crystal silicon (values taken from PC-1D [3]) have been reduced by a factor of 5 to reflect the non-ideal nature of the Silicon-Film material. This estimate was determined from measurements made on Silicon-Film material over a narrow doping range. This modeling method highlights the limited dependence of the Silicon-Film devices on material quality and minority carrier diffusion length.

Figure 3 shows that the efficiency of a $35-\mu \mathrm{m}$-thick device with both light trapping and back surface passivation is superior to that of a conventional device at all doping levels of interest. Peak efficiencies for the thin device are predicted for doping levels in the range of $\mathrm{N}_{\mathrm{a}}=2 \times 10^{17} \mathrm{~cm}^{-3}$ to $5 \times 10^{17} \mathrm{~cm}^{-3}$. These doping levels correspond to diffusion lengths in the range of $40 \mu \mathrm{m}$ to $80 \mu \mathrm{m}$. The efficiencies of the thin devices are predicted to decrease as base doping is decreased (and diffusion length is increased). This is a result of the decreasing $\mathrm{V}_{\mathrm{oc}}$ that occurs at lower doping levels. The same effect occurs in the conventional device, however current increases offset the lower $V_{o c}$ values, and efficiency remains constant.

The limited dependence on diffusion length allows the thin device to use higher base doping levels and therefore achieve high $\mathrm{V}_{\mathrm{oc}}$. This option is not available to thick conventional devices as long diffusion lengths are required to collect minority carriers generated deep in the base layer. The long diffusion length requirement in conventional devices allows high efficiency to be obtained only with high quality, relatively expensive silicon wafers. 


\section{Model Parameters}

A - $\quad 400 \mu \mathrm{m}$ Thick Conventional Device

$\frac{\mathbf{S}_{\mathrm{BACK}}}{10^{6} \mathrm{~cm} / \mathrm{s}}$

Optical Path Length

B - $\quad 35 \mu \mathrm{m}$ Thick Conventional Device

$10^{6} \mathrm{~cm} / \mathrm{s}$

$Z=1$

C - $\quad 35 \mu \mathrm{m}$ Thick Device with Back Surface

$10^{3} \mathrm{~cm} / \mathrm{s}$

$Z=1$

Passivation

D - $\quad 35 \mu \mathrm{m}$ Thick Device with Light-Trapping

$10^{6} \mathrm{~cm} / \mathrm{s}$

$Z=20$

E - $\quad 35 \mu \mathrm{m}$ Thick Device with Light-Trapping

$10^{3} \mathrm{~cm} / \mathrm{s}$

$Z=20$ and Back Surface Passivation

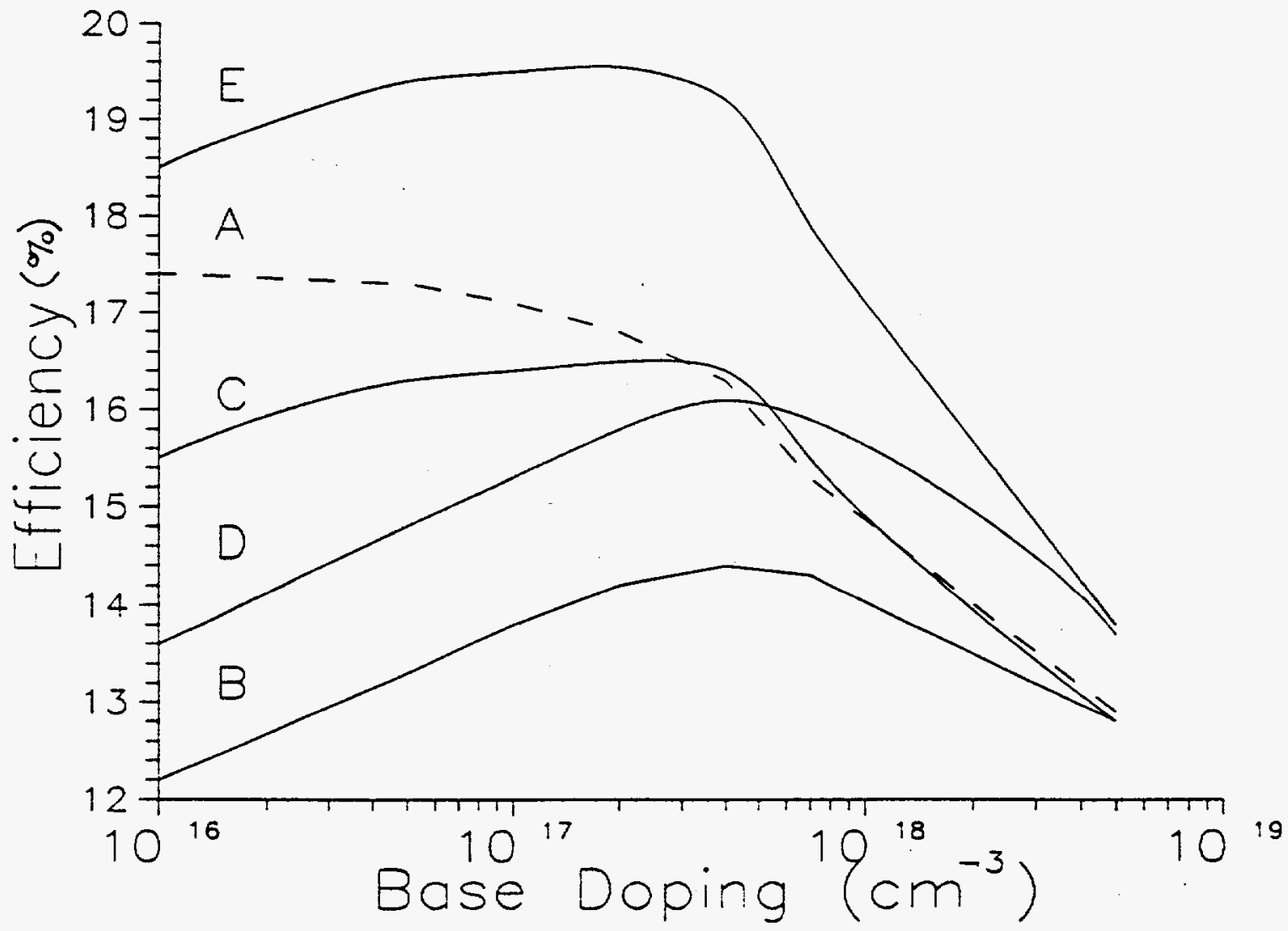

Figure 3. Predicted conversion efficiency (AMISG) as a function of base doping. Diffusion lengths are adjusted to be consistent with doping levels. 


\section{Device Fabrication and Characterization}

\subsection{Conductive Ceramic Substrate}

Control of ceramic conductivity has been achieved through the control of the relative portions of the ceramic composition and the resulting mass density. Early efforts to produce conductive ceramic materials resulted in a resistivity of approximately $50 \Omega \mathrm{cm}$. Contact resistance was monitored through the fabrication of test structures with metal paste contacts on the front and back of isolated $1.0 \mathrm{~cm}^{2}$ ceramic samples. The overall resistance of the low density ceramics with a grown silicon layer was approximately $3 \Omega \mathrm{cm}^{2}$.

Altering the ceramic composition resulted in a more dense, more conductive material. Volume resistivity was lowered to the range of $10 \Omega \mathrm{cm}$ (as measured at Sandia) and contact resistance was lowered to $0.74 \Omega \mathrm{cm}^{2}$. Overall ceramic thickness is $635 \mu \mathrm{m}$, resulting in a substrate that would not significantly affect overall device series resistance.

Ohmic contact was made to the ceramic samples by production screen printing techniques. A silver/aluminum paste was used to form parallel lines on ceramic samples. Printed ceramics were fired in open-air belt furnaces. Resistance measurements could then be made between parallel lines. The resulting data is shown in Figure 4. The ceramic under test was $520 \mu \mathrm{m}$ thick, with printed line widths of $180 \mu \mathrm{m}$ on $0.33 \mathrm{~cm}$ spacings. The contacts were ohmic, with a measured $R_{c}=0.74$ and $0.89 \Omega \mathrm{cm}^{2}$ for the two devices (average of $0.81 \Omega \mathrm{cm}^{2}$ ). This value is slightly greater than that required to minimize impact to device fabrication. Solar cells fabricated on full silicon-on-ceramic structures measured a total series resistance lower than that measured with the test structure. The series resistance of a $1.0 \mathrm{~cm}^{2}$ solar cell was measured to be $0.4 \Omega \mathrm{cm}^{2}$ by Sandia. This difference is due in part to localized thinning of the ceramic in the solar cell structure to assist in contacting. From the data in Figure 4, the resistivity is measured to be 11.7 and $12.1 \Omega \mathrm{cm}$ for the two tests (average $11.9 \Omega \mathrm{cm}$ ). This agrees with the Sandia measurement of $10 \Omega \mathrm{cm}$. 


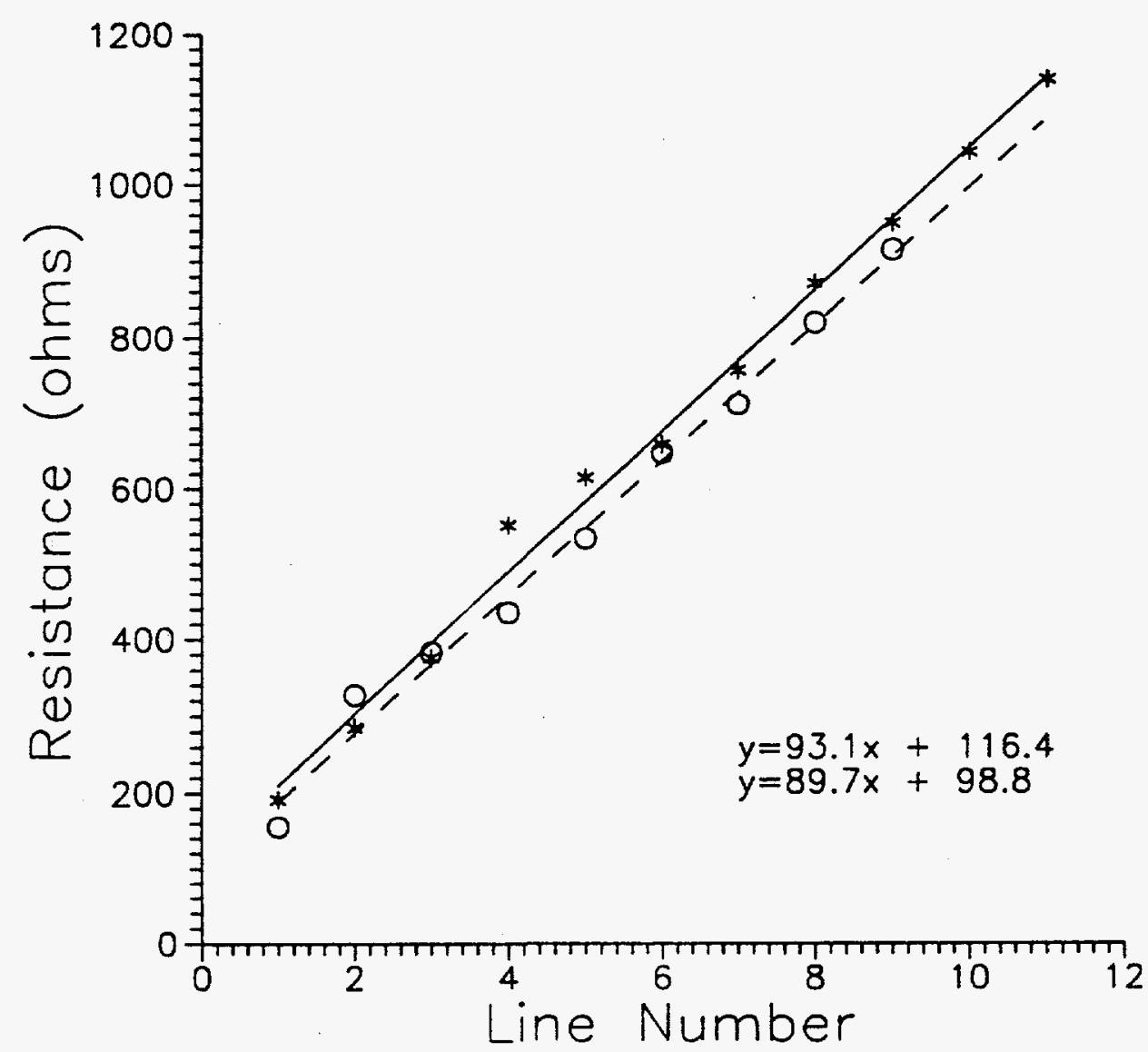

Figure 4. Resistance measurements made on conductivity test structures fabricated on conductive ceramic substrates. The resistance between consecutively numbered parallel lines for two samples is shown. The resulting analysis revealed a contact resistance of $0.81 \Omega \mathrm{cm}^{2}$ and a resistivity of $11.9 \Omega \mathrm{cm}$.

\subsection{Metallurgical Barrier Layer}

The metallurgical barrier (MB) layer plays a critical role in the thin device design. As Figure 3 showed, recombination at the back surface is critical to the overall device efficiency. This recombination will be influenced by the Silicon-Film/MB interface. An effective light trapping design also requires that the interface be reflective to confined light. Additionally, the metallurgical barrier must have the mechanical strength to withstand the silicon deposition process, and it must not be a source of impurities that may have a deleterious effect on device performance. 


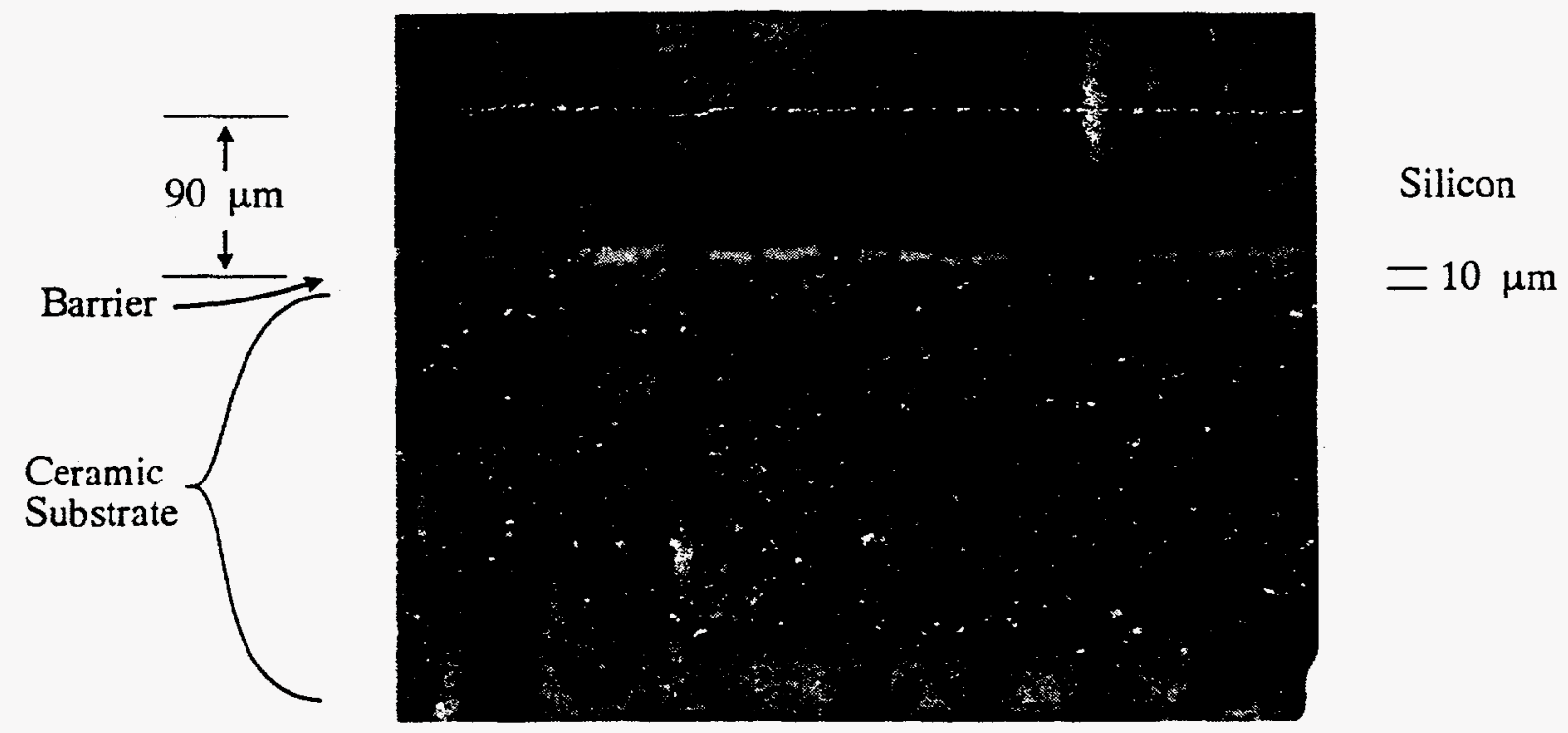

Figure 5. Cross section of a Silicon-Film/metallurgical barrier/textured ceramic substrate structure. Scratches due to polishing.

To satisfy these requirements, barrier layers are formed with combinations of materials including dielectric compounds. The barrier layers are deposited using production-type low-cost processes. Present barrier layers have proven effective at mechanically protecting the Silicon-Film layer from large-scale interaction with the ceramic. A cross section of a Silicon-Film/metallurgical barrier/ceramic structure is shown in Figure 5. The Silicon-Film layer is approximately $75 \mu \mathrm{m}$ thick. The metallurgical barrier layer is approximately $10 \mu \mathrm{m}$ thick. The coarse ceramic can be seen below the barrier layer, and no obvious interaction with the silicon layer is present. Random openings are present in the barrier layer to allow for electrical contact with the ceramic. Much of the scratching of the silicon surface is an artifact from imperfect cross section preparation.

An objective of this work has been to fabricate Silicon-Film layers less than $100 \mu \mathrm{m}$ thick to maximize collection efficiency. A relationship between the thickness of the barrier and the minimal silicon layer thickness that could be grown was determined. Thinner silicon layers could only be achieved by reducing barrier thickness. The thicker barriers used in the formation of silicon layers $200 \mu \mathrm{m}$ thick (similar to that seen in Figure 5) resulted in an irregular silicon surface when thin silicon layers were grown. A thin barrier deposition process was developed that allowed for the growth of 100 - $\mu$-thick silicon layers with smooth surfaces and excellent aspect ratios. 
The reflectivity of the barrier-coated ceramics has been tested. During barrier development, reflectance has been measured from an air/barrier interface. (In the final device configuration, reflection from a silicon/barrier interface is required.) Weakly absorbed light is coupled into the grown silicon layer, reflects off the metallurgical barrier, and is emitted out the front surface. The reflected long wavelength light can be analyzed to determine barrier reflection properties (reflection characteristics are covered in detail in the light trapping section). The final device requires a high reflectivity from a Silicon-Film/metallurgical barrier interface.

Subbandgap reflectance test structures have been fabricated. The resulting measurements have shown the silicon/barrier reflectance to be in the range of $11 \%$ to $52 \%$ (dependent on the assumed internal front surface reflection). This can be compared with similar samples fabricated without a barrier, where the barrier reflection was measured to be $2 \%$ to $27 \%$ percent. The thinner barriers are not as reflective as the thick barriers (which have obtained reflectivities approaching $70 \%$ [4]). Highly reflective thick barriers can be reintroduced to the device structure when the material quality issues are resolved. A more detailed discussion of reflection properties is contained in Section 3.3.1: Reflection Characteristics.

\subsection{Light-Trapping Properties}

Light trapping must be incorporated in thin crystalline silicon films to enhance the absorption of long wavelength light. Light in the wavelength range $0.9 \mu \mathrm{m}$ to $1.1 \mu \mathrm{m}$ is only weakly absorbed in a 50- $\mu \mathrm{m}$-thick silicon film. Of the photons in the AM1.5G spectrum with energy greater than the bandgap of silicon, $24 \%$ are in the wavelength range $0.9-1.1 \mu \mathrm{m}$. Without light trapping, a significant portion of these photons are transmitted through the silicon film and lost.

The back surface of the active Silicon-Film layer must be reflective to internally confined light to effectively trap the light. In conventional thick devices, this high reflectivity can be obtained by the application of metallic layers on the back surface. The high temperatures involved in the processing of the Silicon-Film solar cells do not readily accommodate the use of metallic reflectors. A further requirement on the back surface is that it minimizes recombination. Such performance requirements can be met by a silicon/dielectric interface. 
The light-trapping properties of a solar cell structure can be deduced from the measurements of reflectivity and quantum efficiency. Reflectivity measurements can be analyzed to compute a range of values for the back surface reflectivity (Silicon-Film/ metallurgical barrier interface) [3]. Experimental quantum efficiency measurements indicate higher levels of response for long-wavelength light than predicted by a simple non-light-trapping model. Analysis of these results reveals light-trapping properties.

\subsubsection{Reflection Characteristics}

The reflectance of a Silicon-Film on ceramic structure is shown in Figure 6 with and without a barrier. The increased long-wavelength reflectance of the sample with the barrier is due to light being initially transmitted into the silicon, internally reflected, and then transmitted back out the front. The re-emitted subbandgap light is referred to as the escape reflectance $\left(R_{\text {ESCAPE}}\right)$. $R_{\text {ESCAPE }}$ is defined as the difference between the total subbandgap reflectance $\left(R_{\text {TOTAL }}\right)$ and the external front surface reflectance $\left(R_{F E}\right)$.

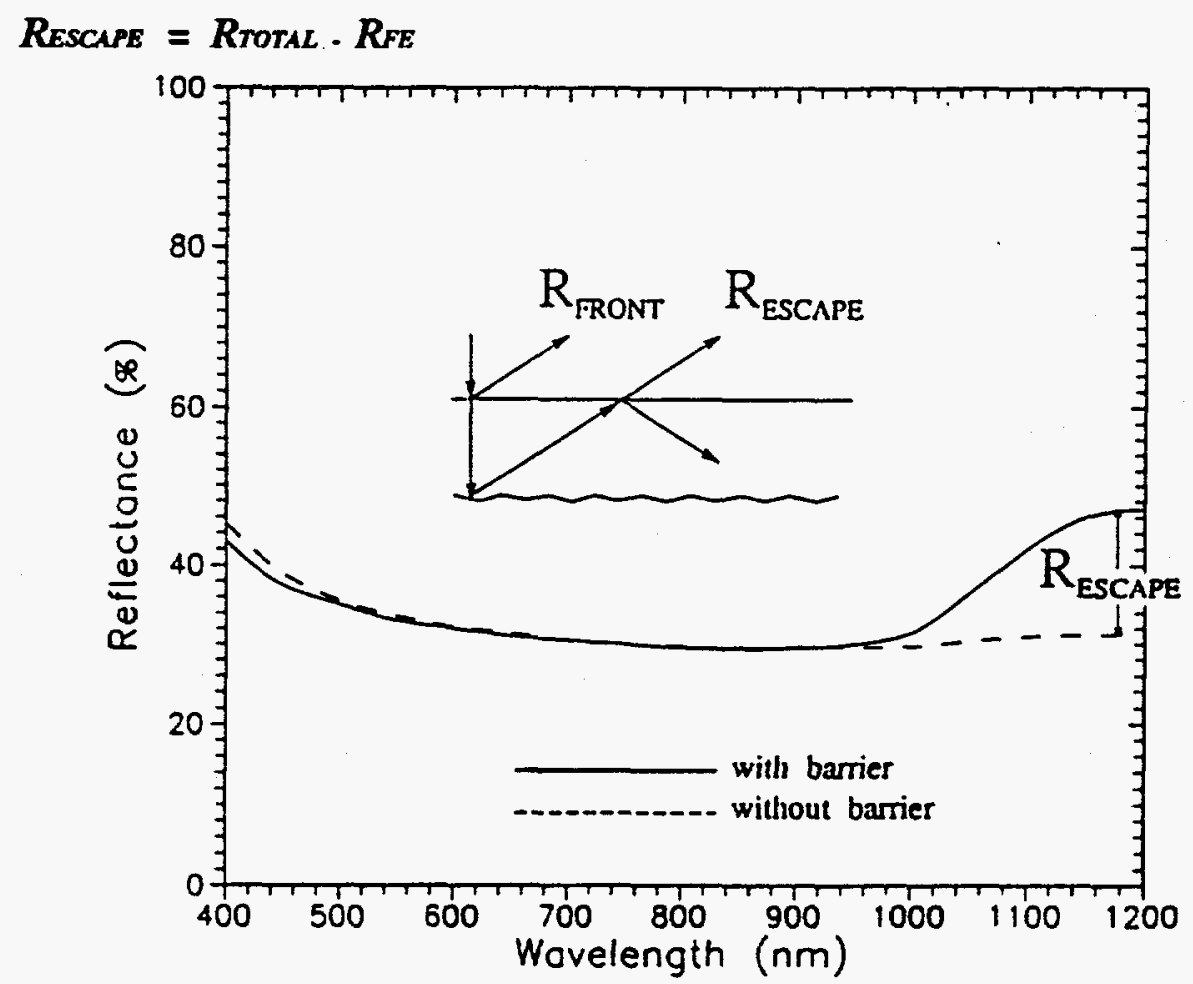

Figure 6. Normalized reflectivity of a Silicon-Film Product II structure. Data is shown for samples fabricated with and without a barrier. 
The silicon-barrier reflectance $\left(\mathrm{R}_{\mathrm{BACK}}\right)$ can be calculated (for non-absorbed light) based on the following relationship [3]

$$
R_{T O T A L}=\frac{R_{F E}\left(1-R_{B A C X}\right)+\left(1-R_{F I}\right)}{1-R_{B A C K} R_{F I}}
$$

where $R_{F I}$ is the internal front surface reflectance. Solving (2) for $R_{B A C K}$ gives

$$
R_{B A C R}=\frac{R_{E S C A P E}}{1-\left(R_{F I}\left(1-R_{E S C A P E}\right)+R_{F E}\left(1-R_{F I}\right)\right)}
$$

The internal front surface reflectance $\left(R_{\mathrm{FI}}\right)$ is an unknown quantity, although minimum and maximum values can be calculated. The minimum value is that of an uncoated silicon/air surface. The maximum is defined by the best-case texturing scheme that would allow for re-direction of the trapped light, and total internal reflection at the silicon/air surface. For this analysis the Lambertian limit of $92 \%$ is used as the best case [5]. This best case assumes the light reflected from the back surface is distributed as the cosine of the angle from the horizontal. The resulting range of barrier reflectance values can be calculated. Table I shows that the presence of the barrier layer increases the net back surface reflectivity to the range of $32 \%$ to $80 \%$.

Table I. Analysis of long-wavelength reflectivity.

\begin{tabular}{|l|c|c|c|r|}
\hline & $\mathbf{R}_{\text {FSCAPE }}$ & $\mathbf{R}_{\mathrm{FF}}$ & $\begin{array}{c}\mathbf{R}_{\mathrm{FT}} \\
\text { Estimated }\end{array}$ & $\mathbf{R}_{\mathrm{BACK}}$ \\
\hline With Barrier & 17.5 & 29.5 & $29.5(\mathrm{~min})$ & 31.9 \\
& & & $92.0(\mathrm{max})$ & 80.5 \\
\hline No Barrier & 1.5 & 29.6 & $29.6(\mathrm{~min})$ & 3.0 \\
& & & $92.0(\mathrm{max})$ & 21.4 \\
\hline
\end{tabular}




\subsubsection{Quantum Efficiency Characteristics}

Quantum efficiency measurements were made on structures with and without barriers. The data for a silicon-on-ceramic sample with a barrier is shown in Figure 7. The silicon layer in the samples under test is $190 \mu \mathrm{m}$ thick. The red response is poor, indicative of material with low minority carrier diffusion length $\left(\mathrm{L}_{\mathrm{N}}\right)$.

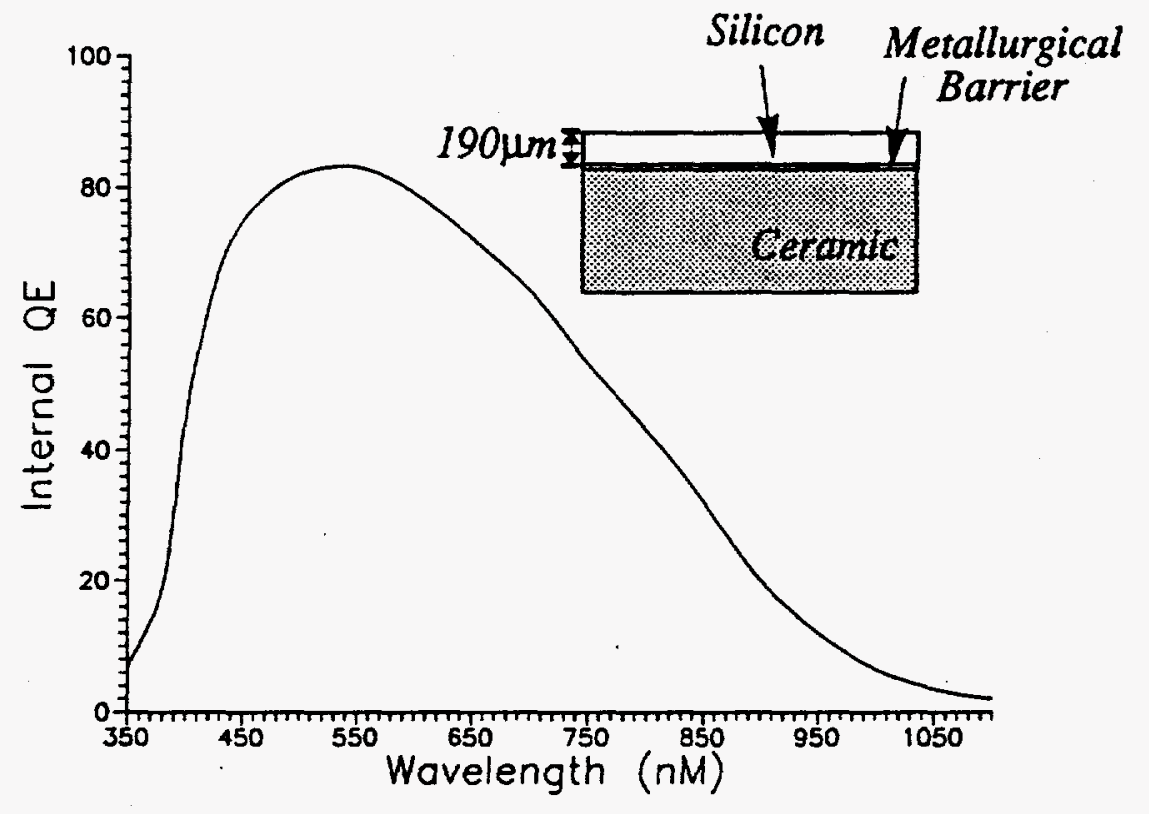

Figure 7. Quantum efficiency of a silicon-on-ceramic structure with a metallurgical barrier layer.

Based on non-light-trapping theory, a measurement of $\mathrm{L}_{\mathrm{N}}$ can be made using internal quantum efficiency data. For a device that has a diffusion length less than the device thickness, and photocurrent from the emitter is negligible, the following relationship exists for weakly absorbed light

$$
\frac{1}{Q E_{\text {INTERNAL }}}=1+\frac{1}{\alpha L_{N}}
$$


This relationship predicts a linear region in the plot of $1 / \mathrm{QE}$ verses $1 / \alpha$. These data are shown in Figure 8 for the QE data from Figure 7. Two linear regions are shown. The first linear region appears when $1 / \alpha<100 \mu \mathrm{m}$. The inverse slope of this line predicts a $\mathrm{L}_{\mathrm{N}}=8 \mu \mathrm{m}$, which can be interpreted as the effective minority carrier diffusion length of the silicon film. The data deviates from simple theory as $1 / \alpha$ exceeds $100 \mu \mathrm{m}$. Higher levels of collection efficiency are recorded than predicted by the simple theory of equation (4). The slope and intercept of this line can reveal detailed properties of the light trapping characteristics [3]. For the device data in Figure 5, a $\mathrm{Z}$ of approximately nine is indicated (where $\mathrm{Z}$ is the optical path length given in multiples of the device thickness). The optical path length of long wavelength light was therefore $1.7 \mathrm{~mm}$ for this $190-\mu \mathrm{m}$-thick film. The low levels of $\mathrm{QE}$ measured at the long wavelengths make the exact evaluation of $\mathrm{Z}$ uncertain. The high level of light trapping seen in the QE data implies a high degree of scattering by the back surface reflector. In this case the internal reflection of the front surface is estimated to approach the Lambertian limit of $92 \%$, and the silicon/barrier interface has a reflectivity of approximately $70 \%$. The details of the lighttrapping model used to generated these parameters are reviewed in the following section.

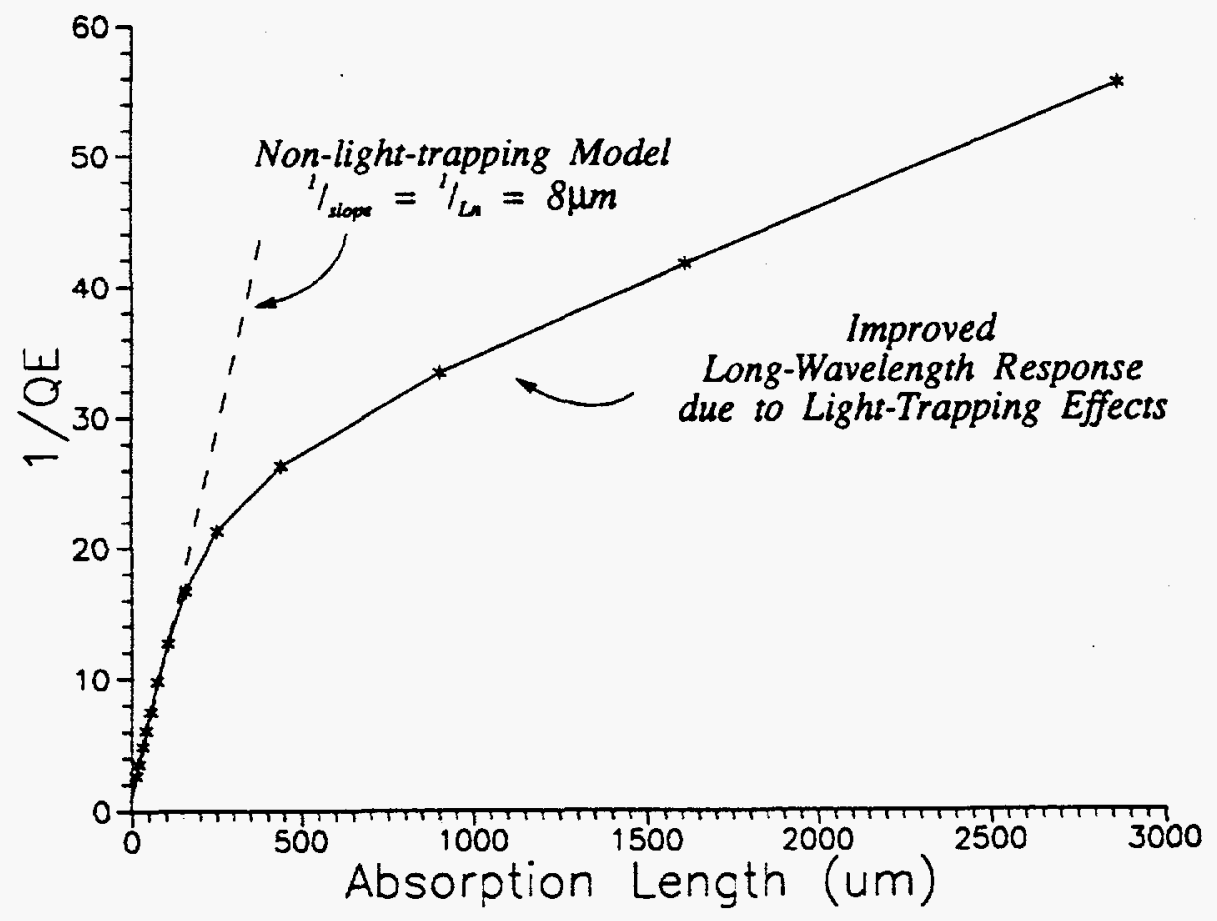

Figure 8. Absorption length versus the inverse of the internal quantum efficiency for the silicon-on-ceramic structure. 


\subsubsection{Light-Trapping Analysis}

A method to identify and quantify light trapping in solar cells has been developed at Sandia and AstroPower [6]. Light-trapping effectiveness depends on the internal reflectivity and texturing of device surfaces. The incorporation of light-trapping features can experimentally be seen in spectral response and reflectance measurements, as well as in the overall light-generated current. Due to the large number of variables that affect light-generated current, an analysis is proposed that evaluates only the optical properties of the structure. The effective optical path length of confined light is proposed as a figure of merit of the optical design. This effective optical path length is shown to be a function of wavelength. Analysis of the nearbandgap light is presented as a monochromatic case with appropriate simplifications. Analyses of thin Silicon-Film solar cells formed on ceramic substrates with and without barriers are presented. Finally, the overall impact of the optical design on the current-generating properties is discussed and an expression for full-spectrum light-trapping effectiveness is defined.

Experimentally, measurements of spectral response and reflectivity are used to evaluate optical properties. Due to the light-trapping nature of the solar cells under evaluation, care must be taken to interpret both measurements correctly. Weakly absorbed light is initially coupled into a device, and after an indeterminate number of internal reflections, is transmitted back out the front surface. This re-emitted light must be distinguished from the light reflected from the front surface initially ( $\mathrm{R}_{\mathrm{FE}}$ vs. $\mathrm{R}_{\mathrm{ESCAPE}}$ as discussed in Section 3.3.1: Reflection Characteristics). As the reflectance is used to calculate the internal quantum efficiency (IQE), this differentiation must be accounted for in the IQE results. These points are further illustrated in the following section on optical path length.

The following sections describe the nomenclature and theory used to evaluate the extended optical path length found in light-trapping solar cells. Sections 3.3.3c and 3.3.3d review the impact of the derived figures of merit on device current- generating capabilities.

Specific theoretical examples are given. Section 3.3.3d also presents a full-spectrum figure of merit, closely related to current-generating properties.

\subsection{3a Model for Effective Optical Path Length}

The optical properties of a light-trapping structure can be characterized by introducing an effective optical path length factor, $Z(\lambda)$, and an effective optical path length factor for 
uniformly absorbed nearbandgap light, $Z_{o}$. The following model also utilizes a collection efficiency term $\eta_{c}(\lambda)$. These terms are defined as:

$\mathbf{Z}(\lambda): \quad$ The wavelength-dependent optical path length of light required to generate absorption equal to that found in the device under test. $\mathrm{Z}$ is expressed as a multiple of the device thickness.

$\mathbf{Z}_{\mathbf{0}}$ : Similar to $\mathbf{Z}(\lambda)$, only limited to nearbandgap light that is weakly absorbed. $\mathbf{Z}_{\mathbf{o}}$ is also expressed as a multiple of the device thickness. A weakly absorbed photon is one in which the absorption length is much greater than the device thickness $(\alpha W<1)$. Such weakly absorbed photons are uniformly absorbed throughout the device thickness.

$\eta c^{(\lambda)}$ : The collection efficiency of photogenerated carriers. For a well-designed silicon device $\eta_{c}$ approaches unity for light in the wavelength range $600-800 \mathrm{~nm}$. For nearbandgap, uniformly absorbed light, $\eta_{c}$ approaches a constant value dependent on the recombination properties of the device.

An expression can be derived for $Z(\lambda)$, based on an extension of the model for a non-light-trapping solar cell [3]. For monochromatic light of wavelength $\lambda$, the photogenerated current $\left(J_{L}\right)$ from the base of a non-light-trapping solar cell of thickness $W$ is

$$
J_{L}(\lambda)=\eta_{c}(\lambda) q F(\lambda)\left(1-R_{\text {TOTAL }}(\lambda)\right)\left(1-e^{-\alpha(\lambda) w}\right)
$$

where the incident photon flux density is represented by $F, q$ is the elementary charge, and $\alpha$ is the absorption coefficient. $R_{\text {Total }}(\lambda)$ represents the experimentally measured light leaving the front surface (as defined in Section 3.3.1: Reflection Characteristics). The internal quantum efficiency is conventionally defined as

$$
\operatorname{IQE}(\lambda)=\frac{J_{L}(\lambda)}{q F(\lambda)\left(1-R_{\text {TOT } A}(\lambda)\right)}=\eta_{c}(\lambda)\left(1-e^{-\alpha(\lambda) w}\right)
$$

For a light-trapping structure, the simple front-surface reflection term becomes slightly more complex. An example of the reflection from a light-trapping solar cell [4] was shown in Figure 6. 
An internal quantum efficiency measurement based on either $R_{\text {Total }}(\lambda)$ (defined as IQE) or $R_{\text {Front }}(\lambda)$ (defined as IQE $E_{L T}$ ) can be defined. Equation (6) can be restated for a light-trapping structure using $R_{\text {Front }}$ in place of $R_{\text {Total }}$.

$$
\operatorname{IQE} L T(\lambda)=\frac{J_{L}(\lambda)}{q F(\lambda)\left(1-R_{F R O N T}(\lambda)\right)}
$$

The internal quantum efficiency for a light-trapping solar cell (IQE $\left.E_{L T}\right)$ only considers $R_{F r o n t}$ as light not available for collection. Note that this quantity, $\operatorname{IQE}_{L T}(\lambda)$, is not the quantity computed from experimental measurements of spectral response and reflectance, because the experimentally measured reflectance is $R_{\text {Total }}$, not $R_{\text {Front }}$. The $I Q E_{L T}$ is not directly measurable, as $R_{\text {Front }}$ is not measurable in a light-trapping solar cell. $R_{\text {Front }}$, however, can be approximated from the total reflectance data by extrapolating from shorter wavelengths through the escape-reflectance regime (Figure 6), making the approximation of $\mathrm{IQE}_{\mathrm{LT}}$ possible. The relationship between the conventional $\operatorname{IQE}(\lambda)$ and $\operatorname{IQE}_{\mathrm{LT}}(\lambda)$ is

$$
\operatorname{IQE}(\lambda)_{L T}=\operatorname{IQE}(\lambda)\left[\frac{1-\operatorname{RTOTAL}(\lambda)}{1-\operatorname{RFRONT}_{\sin }(\lambda)}\right]
$$

To account for the extended path length found in light-trapping structures and the resulting additional absorption of nearbandgap light, the device thickness (W) in equation (6) is replaced by the effective optical path length, $Z(\lambda) W$.

$$
\operatorname{IQE} L T(\lambda)=\eta_{c}(\lambda)\left(1-e^{-\alpha(\lambda) Z(\lambda) w}\right)
$$

Solving for $Z(\lambda)$;

$$
Z(\lambda)=\frac{-1}{\alpha(\lambda) W} \ln \left[1-\frac{I Q E_{L T}(\lambda)}{\eta_{c}(\lambda)}\right]
$$

Examining equations (10), it can be seen that $Z$ is not directly measurable, because in general $\eta_{c}(\lambda)$ is not known. The IQE $E_{L T}$ is also not directly measurable; however, it can be approximated 
as discussed above.

The determination of $\eta_{c}(\lambda)$ requires knowledge of the ray path angles, internal reflectance, minority carrier diffusion length, and back surface recombination velocity. Simplifications are possible in two regimes: for uniform photogeneration (nearbandgap wavelengths) and when $\eta_{\mathrm{c}}$ approaches unity.

Experimentally determined values of $Z(\lambda)$ for a light-trapping structure are shown in Figure 9. The quantum efficiency for this silicon-on-ceramic device is shown in Figures 7 and 8. Values of $\eta_{c}$ have been estimated from the analysis of nearbandgap light presented below. The effective optical path length of the AstroPower device begins to saturate at a value approaching $\mathrm{Z}=7.5$. The longest wavelength measurements are subject to experimental error as the IQE reading approaches zero.

For the case of uniformly-absorbed nearbandgap light, simplifying assumptions allow $\mathrm{Z}_{\mathrm{o}}$ to be extracted directly from measurable quantities. The optical model, based on experimental assumptions, is presented below.

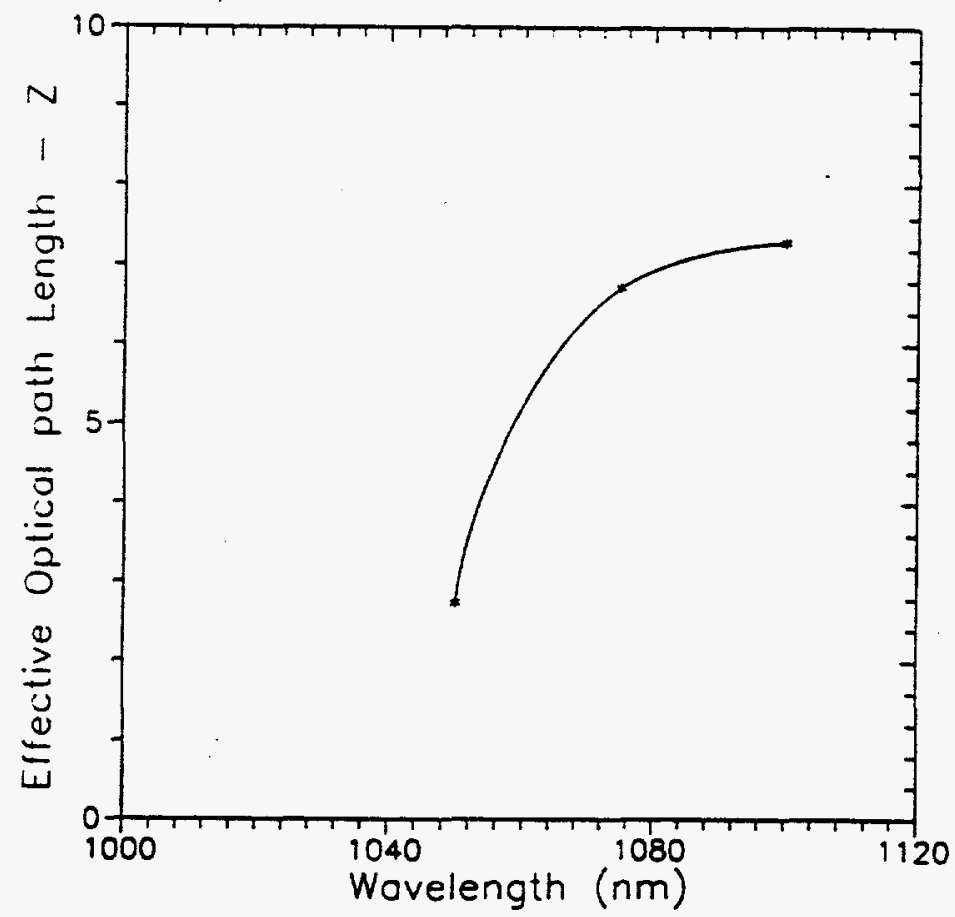

Figure 9. $Z(\lambda)$ for an AstroPower silicon-on-ceramic device as derived from equation (10). 


\subsection{3b Modeling for the Nearbandgap Case}

Limiting the analysis of the spectral response and reflectivity to the nearbandgap light, a model-based analysis has been developed at Sandia that determines the effective optical path length $\left(\mathrm{Z}_{\mathrm{o}}\right)$ based on experimental data. Considering non-absorbed light, an expression for the $Z_{o}$ can be derived $[3,6,7]$;

$$
Z_{0}=\frac{W_{l Q E}}{\eta_{c W} w} \frac{\left(1-R_{\text {TOTAL }}\right)}{\left(1-R_{F R O N T}\right)}
$$

where $\mathrm{W}_{\mathrm{IQE}}$ represents the inverse slope of a IQE ${ }^{-1}$ vs. $\alpha^{-1}$ plot when $\alpha^{-1} \gg \mathrm{W} / \cos \theta_{\mathrm{n}}$, and $\eta_{\mathrm{c}}$ is the collection efficiency of photogenerated minority carriers. $\eta_{c}$ is related to the $y$-intercept, $1 / \eta^{\prime}$, of the IQE ${ }^{-1}$ vs. $\alpha^{-1}$ curve [8].

$$
\eta_{c}=\eta_{c}^{\prime}\left[\frac{1}{2}+\frac{2 \rho_{B}}{\left(1+\rho_{B}\right)^{2}}\right]
$$

where $\rho_{B}$ is the back-surface reflectance. Making certain assumptions regarding the distribution of confined light within the device [3], a value of $\rho_{B}$ can be determined, and $Z_{O}$ can be computed from the other experimentally measured values. For $\rho_{B}>0.5, \eta_{C}$ can be replaced directly with $\eta_{c}{ }^{\prime}$ in equation (11) and accuracy will remain within $5 \%$.

This analysis has been carried out for a Silicon-Film device formed with a metallurgical barrier (Figure 10) and a Silicon-Film device formed without a metallurgical barrier (Figure 11). For the silicon-on-ceramic device with a barrier, $R_{\text {Total }}(\lambda=1200 \mathrm{~nm})=0.29, \rho_{B}=0.72$, and $R_{\text {Front }}=0.14$, for the $190-\mu \mathrm{m}$-thick silicon layer. The resulting $Z_{o}$ estimate of 9.1 compares favorably to the $Z(\lambda)$ data shown in Figure 9 for the same device. Differences in the two methods may be due to inconsistencies in the optical path length in the device as compared to the model.

Data for the silicon-on-ceramic device without a barrier are shown in Figure 11. Optical characteristics of the device are $R_{\text {Total }}(\lambda=1200 \mathrm{~nm})=0.21, \rho_{B}=0.33$, and $R_{\text {Front }}=0.11$, for the 109- $\mu \mathrm{m}$-thick silicon layer. Due to the low $\rho_{B}$ in this case, $\eta_{c}=0.87 \eta_{c}^{\prime}$. Even with the low back surface reflectivity, $a Z_{o}=3.3$ is achieved in the device with no barrier. 
This modeling-based approach has the advantage of determining $Z_{o}$ at much shorter wavelengths than the $Z(\lambda)$ approach presented earlier. Experimental error will therefore be less significant. 


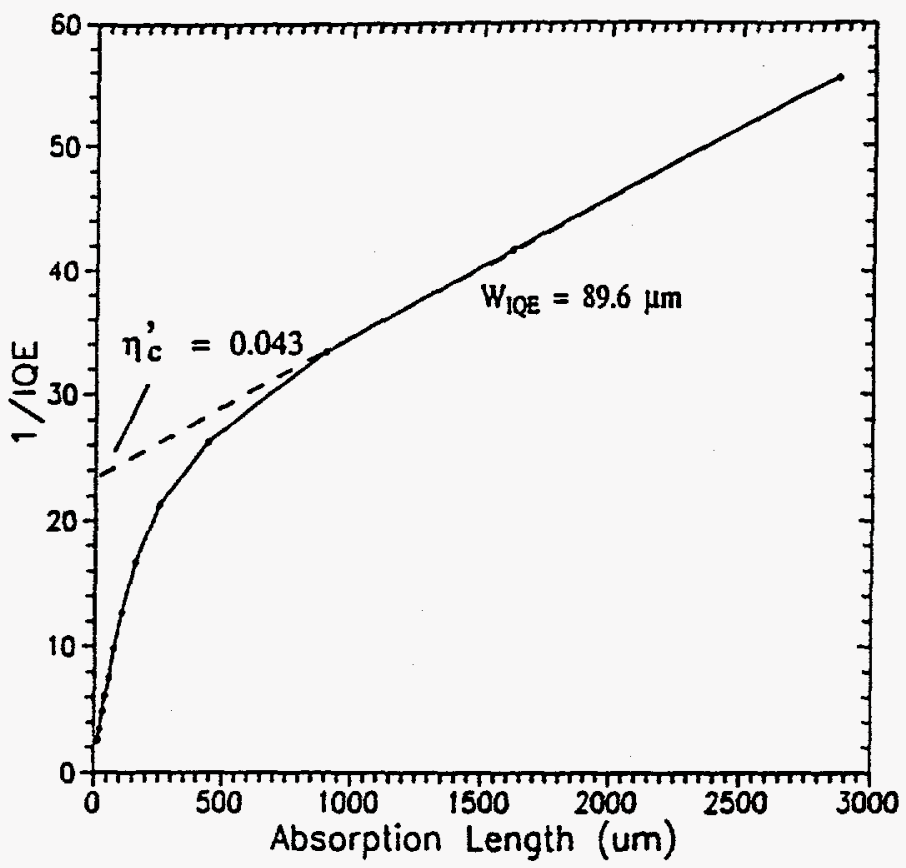

Figure 10. Analysis of the nearbandgap spectral response of a silicon-on-ceramic device formed with a metallurgical barrier revealing $\eta_{c}{ }^{\prime}=0.043$ and $W_{1 Q E}=89.6 \mu \mathrm{m}$, resulting in a $Z_{o}=9.1$.

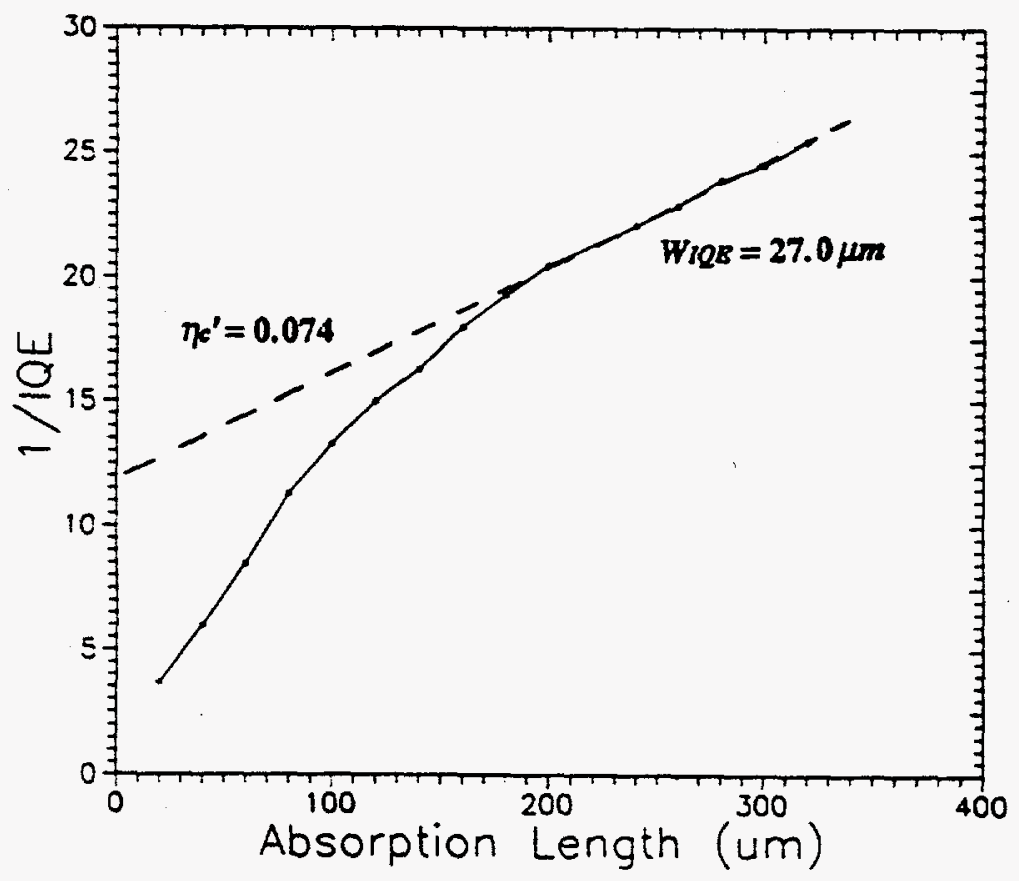

Figure 11. Analysis of the nearbandgap spectral response of a silicon-on-ceramic device formed without a metallurgical barrier revealing $\eta_{c}{ }_{c}^{\prime}=0.074$ and $W_{I Q E}=27.0 \mu \mathrm{m}$, resulting in $a Z_{o}=3.3$. 


\subsection{3c Optical Effects on Light-Generated Current}

The purpose of light trapping is to enhance the light-generated current of a photovoltaic device. Although significant light-trapping information can be extracted from the nearbandgap quantum efficiency and reflectivity, the most critical response is in the wavelength range of 800 to $1100 \mathrm{~nm}$ (dependent on the thickness of the device). This range is important due to the relatively high solar energy available and the relatively high absorption coefficient. To fully evaluate a light-trapping structure the shape of the $Z(\lambda)$ curve must be analyzed.

To highlight the impact of the shape of the $Z(\lambda)$ curve on $J_{s c}$ two theoretical examples are given below (Figure 12). These devices were chosen to have the same nearbandgap effective optical absorption length. The first example, case (a), is for a device that utilizes a regularly textured back surface. All the light follows the same path, which generates an optical path length 5 times the device thickness ( $\mathrm{Z}=5$ for $100 \%$ of the light). The second example is a device with a randomly textured back surface that has a poor back surface reflectivity (case (b)). The portion of light that is reflected from the back surface in case (b) travels obliquely through the device, and is modeled as having an optical path length of $20(Z=20$ for $20 \%$ of the light, $Z$ $=1$ for $80 \%$ of the light, net $Z=5$ ). Such a situation would occur if the back surface reflector was randomly textured, and total internal reflection was the dominant mechanism for optical confinement. Any internally reflected light would therefore have to strike the back surface at an angle of incidence greater than some critical angle (dependent on the indices of the interface materials). This internally reflected light would then be traveling obliquely through the device, making reflection from the front surface probable, for a long effective optical path length.

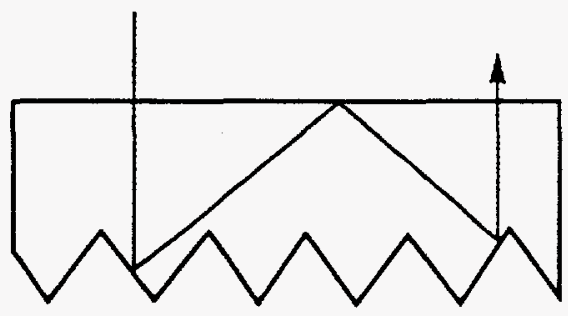

(a)

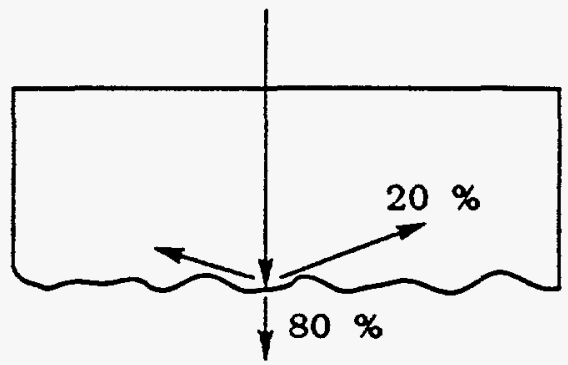

(b)

Figure 12. Two theoretical cases of light-trapping structures that generate similar nearbandgap absorption but differ greatly in current-generating properties. Case (a) confines all the light for an optical path length 5 times the device thickness. Case (b) transmits $80 \%$ of the light initially, but retains $20 \%$ for an optical path length 20 times the device thickness. 
The light-generated current from these two extreme cases can be calculated using a model that computes the current generated by each subsequent pass of the light [2]. The model assumes no losses to external front-surface reflectivity, and carrier collection is unity $\left(\eta_{c}=1.0\right)$.

The effective optical path-length factors, $Z(\lambda)$, for both structures shown in Figure 12 have been computed according to equation (10). The results are shown in Figure 13. Case (a), where $100 \%$ of the light is confined for an optical path length 5 times the thickness, reaches is nearbandgap value of $Z=5$ at a wavelength of less than $1000 \mathrm{~nm}$. By comparison, case (b) does not reveal significant light-trapping properties until much longer wavelengths. This effect can also be seen in the theoretical $\mathrm{J}_{\mathrm{sc}}$ values for the two devices under an AM1.5G spectrum. For a device thickness of $100 \mu \mathrm{m}$, case (a) generates $J_{s c}=40.3 \mathrm{~mA} / \mathrm{cm}^{2}$ (8.3\% higher than an equivalent thickness without any light trapping) while case (b) generates $38.3 \mathrm{~mA} / \mathrm{cm}^{2}(2.9 \%$ higher than non-light-trapping device).

The effect on $\mathrm{J}_{\mathrm{sc}}$ becomes more pronounced as the device thickness is reduced. For a 35 $\mu \mathrm{m}$-thick device, the current generated by case (a) is $13.1 \%$ higher than the non-light-trapping case, while case (b) is $4.1 \%$ higher.

The calculation of $Z(\lambda)$ over the entire wavelength range of interest is possible in this theoretical case because a collection efficiency of unity $\left(\eta_{c}=1.0\right)$ was assumed. A similar calculation can be made for an experimental device if $\eta_{c}(\lambda)$ is explicitly known or can be accurately estimated over the wavelength range of interest.

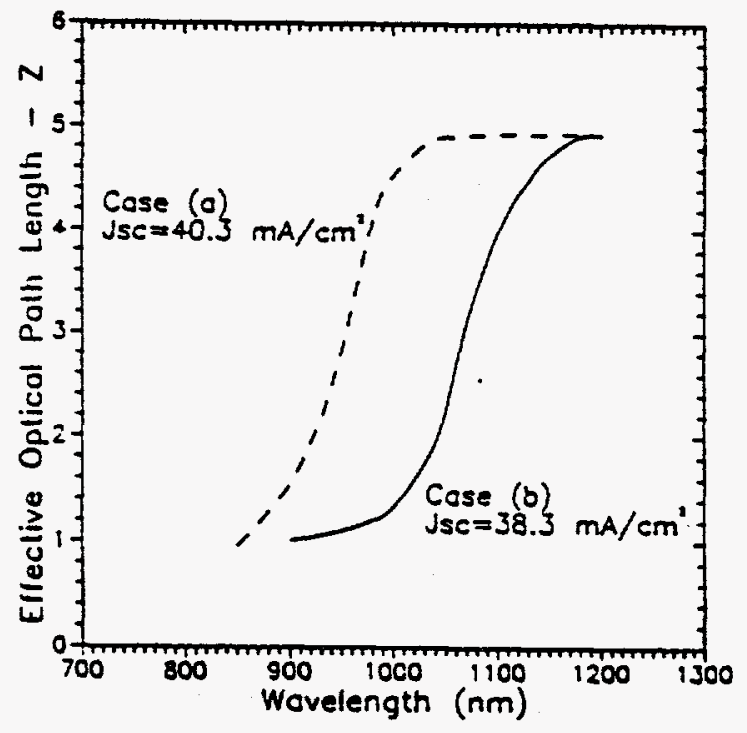

Figure 13. The theoretical effective optical path length of the two devices portrayed in Figure 12. 


\subsection{3d Full-Spectrum Light-Trapping Effectiveness}

A full-spectrum light-trapping effectiveness term has been developed at Sandia and AstroPower that evaluates $Z(\lambda)$ and the photon flux density across a given spectrum. A figure of merit is generated that is related to the current-generating capabilities of a device for a given solar spectrum.

The total photon absorption ( $\Gamma$ for the AM1.5G spectrum can be established from the measured value of $J_{L}$ and an estimate of $\eta_{C}$ to be

$$
\Gamma=\int \text { wel.sc } \frac{J_{L}(\lambda)}{q \eta_{c}(\lambda)} d \lambda
$$

An equivalent determination of the total photon absorption can be modeled utilizing an effective device thickness, $\mathrm{W}^{\prime}=\mathrm{Z}(\mathrm{AM} 1.5 \mathrm{G}) \mathrm{W}$.

$$
\Gamma=\int \min _{1 . s c} F(\lambda)\left(1-R_{\text {FRONT }}(\lambda)\right)\left(1-e^{-\alpha(\lambda) w^{\prime}}\right) d \lambda
$$

Equations (13) and (14) can be equated and rearranged as

$$
\int \omega_{1 . s G} \frac{q F(\lambda) \operatorname{IQE} L T(\lambda)}{\eta_{c}(\lambda)} d \lambda=\int \mu_{1 . . s c} q F(\lambda)\left(1-e^{-\alpha(\lambda) w^{*}}\right) d \lambda
$$

For a given spectrum, the right-hand side of equation (15) represents the total photogenerated current for an absorption thickness W'. Figure 14 shows photogenerated current (AM1.5G) as a function of absorption thickness, W'. The left hand side of equation (15) can be calculated utilizing spectral response, reflectance data, and an estimate of $\eta_{c}$. Finding the absorption thickness $\left(W^{\prime}\right)$ on Figure 14 that corresponds to this current and dividing by the device thickness will give $\mathrm{Z}$ (AM1.5G).

The light-generated currents of the theoretical structures shown in Figures 12 and 13 can be used directly in this analysis since they were modeled assuming $\eta_{c}=1.0$ and no external frontsurface reflection. The $\mathrm{Z}(\mathrm{AM} 1.5 \mathrm{G})$ can therefore be calculated to be 5.0 for case (a) and 
approximately 1.5 for case (b). This analysis shows that two device structures with the same $Z_{o}$ can have significantly different current generating properties and full-spectrum light-trapping effectiveness.

\section{Silicon Photogeneration AM1.5G, 25C}

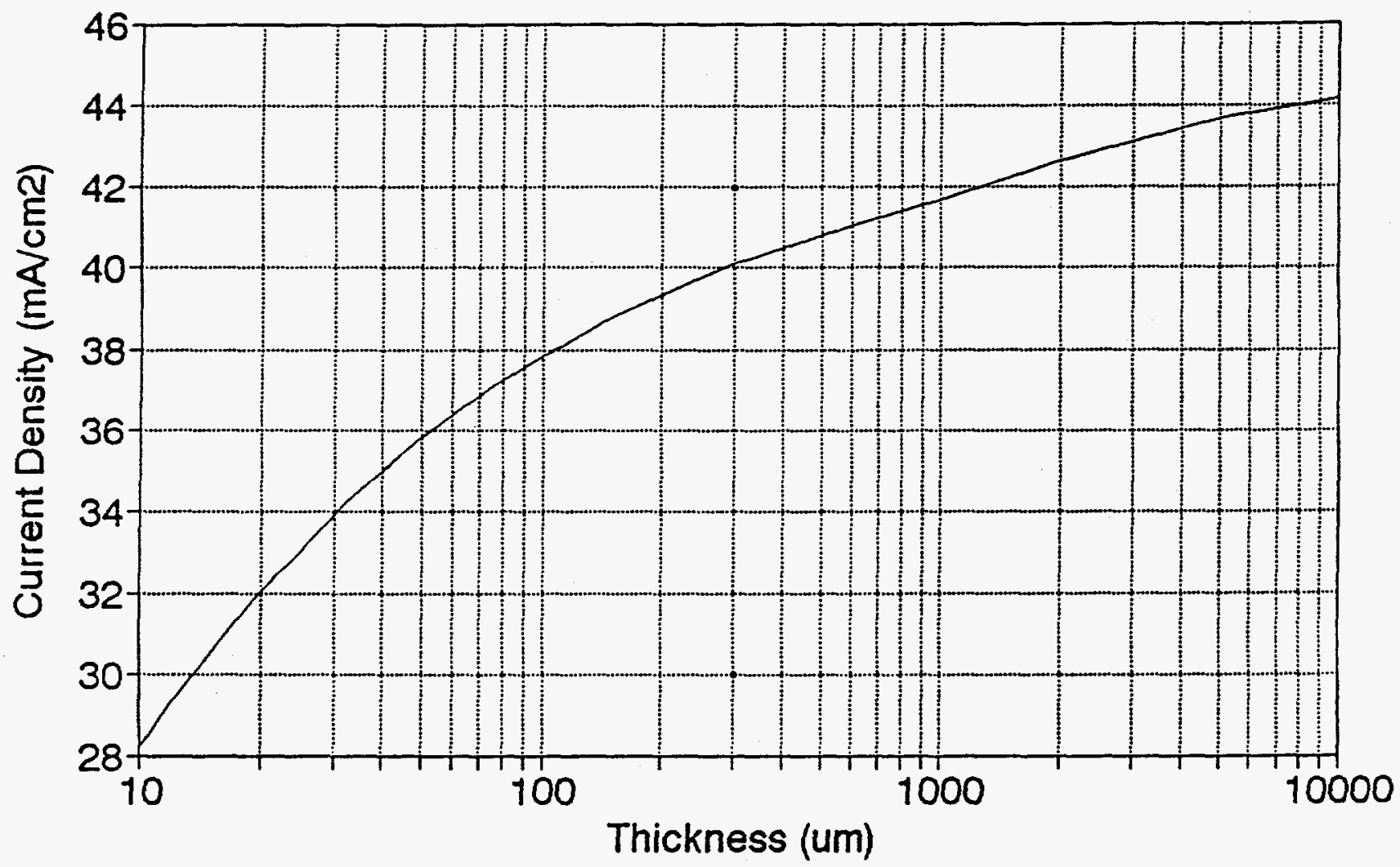

Figure 14. The photogeneration in silicon for the $A M 1.5 \mathrm{G}$ spectrum at $25^{\circ} \mathrm{C}$, as a function of absorption thickness [8]. 
Thin Silicon Solar Cells 


\section{Solar Cell Device Results}

Silicon-Film on ceramic structures have been fabricated into $1.0 \mathrm{~cm}^{2}$ devices utilizing standard solar-cell processing techniques. The full process sequence is shown in Table II.

Table II. Device Processing Sequence.

\begin{tabular}{|c|c|}
\hline Surface Etch & - $\quad 30$ second chemical polish etch \\
\hline Pre-Diffusion Clean & - $\quad$ Modified RCA clean \\
\hline Diffusion & $\begin{array}{ll}\text { - } & \mathrm{PH}_{3} \text { source } \\
\text { - } & 840^{\circ} \mathrm{C} \\
\text { - } & 5 \mathrm{~min} . \text { pre-deposition } \\
\text { - } & 15 \mathrm{~min} . \text { drive-in } \\
\text { - } & \text { HF strip } \\
\end{array}$ \\
\hline P-Type Contact & $\begin{array}{l}\text { - } \quad \text { Screen Printed Al paste } \\
\text { - } \quad 880^{\circ} \mathrm{C} \text { Fire in open-air belt furnace }\end{array}$ \\
\hline N-Type Contact & $\begin{array}{ll}\text { - } & \text { Define metallization areas with photoresist } \\
\text { - } & \text { Evaporate Ti/Pd/Ag } \\
\text { - } & \text { Lift-off unwanted metal } \\
\text { - } & \text { Electroplate Ag } \\
\end{array}$ \\
\hline Isolation & $\begin{array}{l}\text { - Mask active area with photoresist } \\
\text { - } \quad \text { Plasma etch } 5-8 \text { min. } \\
\text { - } \quad \text { Photoresist strip } \\
\end{array}$ \\
\hline Test & - $\quad$ AM1.5G \\
\hline
\end{tabular}

A brief surface etch was used to generate uniform surfaces for all devices fabricated. This etch was not required in all cases. The silicon deposition process generates silicon-onceramic structures with very clean, low-defect surfaces, capable of going directly into emitter formation with little change noted in device performance. 
In results verified by Sandia, an AM1.5G efficiency of $6.6 \%$ was measured. Specific results are shown in Table III.

Table III. Measured I-V Characteristics on $1.0 \mathrm{~cm}^{2}$ Silicon-Film Product II.

\begin{tabular}{|l|l|l|l|l|}
\hline & $\begin{array}{c}\mathbf{V}_{\text {oc }} \\
(\mathbf{m V})\end{array}$ & $\begin{array}{c}\mathbf{J}_{\text {sc }} \\
\left(\mathbf{m A} / \mathbf{c m}^{2}\right)\end{array}$ & \multicolumn{1}{|c|}{$\mathbf{F}$} & $\begin{array}{c}\eta \\
(\%)\end{array}$ \\
\hline $\begin{array}{l}\text { Sandia Verified Device } \\
(9 / 90)\end{array}$ & 513 & 19.3 & 65.8 & 6.6 \\
\hline
\end{tabular}

Improvements in device processing, and changes in doping levels, have increased $V_{\propto}$ and FF in more recent samples. $A V_{\propto}$ of $546 \mathrm{mV}$ and a FF of 70.2 have been measured. Overall $\mathrm{J}_{\mathrm{sc}}$ values remain low, limited by poor minority-carrier diffusion length $\left(\mathrm{L}_{\mathrm{N}}\right)$. Values for $\mathrm{L}_{\mathrm{N}}$ have been in the range of 5 to $10 \mu \mathrm{m}$.

Investigations of the cause of the low minority carrier diffusion length include analysis of stress-induced defects, grain-boundary losses, and impurities. Through the use of test structures and defect etching, stress has been found to play a small role. Defect densities (measured after Secco etching) have been found to be as low as $3 \times 10^{5} \mathrm{~cm}^{-2}$. Residual stresses have been low, as no warping or cracking has occurred over the $50 \mathrm{~cm}^{2}$ areas presently under development. Grain-boundary recombination effects are also insignificant as columnar grains are formed with aspect ratios exceeding 10 . Chemical analysis has shown significant levels of metallic impurities.

Chemical analysis of Silicon-Film samples and silicon feedstock were initially conducted by Sandia National Laboratories. The results indicated that high levels of metallic impurities were present in both the silicon feedstock and grown Silicon-Film layers. Levels of iron and chromium were found in the $10 \mathrm{ppm}$ level. This compares poorly to the concentration level that causes $10 \%$ degradation in single-crystal cells ( $0.01 \mathrm{ppm}$ for $\mathrm{Fe})$. The measured concentration levels could easily explain the poor recombination properties of the material. Measurements were made by inductively coupled plasma mass spectrometry (ICP-MS). 
The discovery of metallic impurities initiated a materials and processing investigation to understand contamination sources. A second silicon vendor was found. All process steps were closely scrutinized. Chemical analysis by neutron activation was utilized to help in determining impurity sources and highlighting problem process steps. The new feedstock and improved handling was successful in lowering metallic impurity levels to the detection limit of the neutron activation analysis (approximately $1 \mathrm{ppm}$ ). Although improved, Fe could still be present in levels high enough to significantly impact device results.

The incorporation of high levels of oxygen was investigated as a cause of the poor minority-carrier recombination properties. To investigate the effects of oxygen, test structures were fabricated with oxygen-rich $\mathrm{CZ}$ single-crystal wafers and oxygen-deficient float-zone (FZ) single-crystal wafers. The test structures were put through the same thermal sequence as Silicon-Film samples receive during growth and device processing. The results indicated that both $\mathrm{FZ}$ and $\mathrm{CZ}$ reacted similarly, indicating that the thermal sequence used does not activate oxygen impurities. This data agrees with earlier experiments performed with silicon-on-ceramic samples. Silicon-Film samples were heat treated in a fashion to minimize the formation of oxygen precipitates, while similar samples were heat treated to maximize precipitate formation. Devices formed on the heat treated samples remained similar to controls that saw neither heat treatment. It was therefore concluded that oxygen was not presently limiting device performance.

Samples of Silicon-Film on ceramic have been evaluated by Secco etching. Levels of defects are compared to Silicon-Film Product I structures that were run through the Product II processing equipment. Before defect etching, mesa devices were formed, and minority carrier diffusion length measured. The results are shown in Table IV.

Table IV. Defect density measured on Silicon-Film Products.

\begin{tabular}{|l|c|c|}
\hline & $\mathrm{L}_{\mathrm{N}}$ & Defect Density \\
\hline Product I Sample & $31-56 \mu \mathrm{m}$ & $2-10 \times 10^{5} \mathrm{~cm}^{-2}$ \\
\hline Product II Sample & $<5 \mu \mathrm{m}$ & $8 \times 10^{5} \mathrm{~cm}^{-2}$ \\
\hline
\end{tabular}


For the Product II structure the majority of defects were clustered near the grain boundaries. Intra-grain regions of the Product II device look as good, or better, than the corresponding Product I sample. Product $\Pi$ aspect ratios continue to be large, with grain sizes in excess of $500 \mu \mathrm{m}$. Recombination at the grain boundaries alone can not be driving the poor Product II diffusion length. The large disparity in $\mathrm{L}_{\mathrm{N}}$ between the two samples is a continuing area of investigation, highlighting sources of impurities. Differences between the Product I and II processes include silicon deposition techniques and the presence of the metallurgical barrier. 


\section{Conclusion}

The Silicon-Film on ceramic structure has been designed to generate high efficiency utilizing imperfect materials. This design involves thin silicon layers in light-trapping structures. Excellent optical characteristics have been measured, with silicon/barrier back surface reflectivities of $70 \%$, and optical path lengths nine times the device thickness. Device efficiency has been limited to $6.6 \%$ in $1.0 \mathrm{~cm}^{2}$ devices by low minority-carrier diffusion lengths. Impurities have been identified as the leading cause of the poor recombination characteristics. Actions are being taken to identify and control the contamination sources.

Conductive ceramic substrates have been developed at AstroPower with resistivities of approximately $10 \Omega \mathrm{cm}$. This ceramic was found to be easily contacted with screen printed metal pastes. Contact resistance is slightly higher than required for optimal device operation and further development of firing conditions is needed.

A method to identify and quantify light trapping in solar cells has been presented. The results indicate that a wavelength-dependent figure of merit, describing light absorption, can be generated. This figure of merit is the effective optical path length of weakly absorbed light. A limiting case of the optical path length can be found through a modeling-based analysis of the nearbandgap light. The wavelength-dependent optical path length can also be analyzed to generate a full-spectrum light-trapping effectiveness term for a given solar spectrum. This full-spectrum effectiveness is closely related to the device's current-generating capabilities.

The test results of two experimental light-trapping devices were analyzed. The analysis of the experimental devices, and specific theoretical test cases, reveal that accurate analysis of the current-generating properties of specific devices requires careful examination of light trapping properties as a function of wavelength. Results indicate that the back surface reflectivity plays a critical role in the current-generating properties of light-trapping solar cells. 


\section{References}

[1] A.M. Barnett et al, 26th Intersociety Energy Conversion Engineering Conference, (American Nuclear Society, La Grange Park, IL, 1991), pp.101-105.

[2] J.A. Rand, R.B. Hall, and A.M. Barnett, 21st IEEE Photovoltaic Specialist Conference, (IEEE Press, New York, NY, 1990), pp.263-268.

[3] P.A. Basore, IEEE Transactions on Electron Devices 37(2), 337(1990).

[4] J.A. Rand, D.H. Ford, C. Bacon, A.E. Ingram, T.R. Ruffins, R.B. Hall, and A.M. Barnett, 10th E.C. Photovoltaic Solar Energy Conference, (Kluwer Academic Publishers, Dordrecht, The Netherlands, 1991), pp.306-309.

[5] A. Goetzberger, 15th Photovoltaic Specialists Conference, (IEEE, New York, NY, 1982), pp. 882-889.

[6] J.A. Rand and P.A. Basore, 22nd IEEE Photovoltaic Specialist Conference, (IEEE Press, New York, NY, 1991), pp.192-197.

[7] P.A. Basore, 1990 DOE/Sandia Crystalline Photovoltaic Technology Project Review Meeting, (National Technical Information Services, Springfield, VA., 1990), pp.123-126.

[8] P.A. Basore, Personal Communication, December 1991. 
Distribution:

\section{Alpha Solarco (2) \\ Attn: Edward Schmidt \\ Donald Carroll \\ 11534 Gondola Drive}

Cincinnati, OH 45241

Amonix, Inc. (2)

Attn: Sewang Yoon Vahan Garboushian

3545 West Lomita Boulevard

Unit A

Torrance, CA 90505

Applied Solar Energy Corp. (2)

Attn: Frank Ho Henry Yoo

15251 East Don Julian Road

City of Industry, CA 91746

Arizona State University (2)

College of Engineering and

Applied Science

Attn: Robert Hammond

Charles Backus

Tempe, AZ 85287-5806

AstroPower

Attn: Allen Barnett

Solar Park

Newark, DE 19716

Black and Veatch

Attn: Kevin Kerschen

Post Office Box 8405

Kansas City, MO 64114

Boeing Aerospace

Attn: Dr. John W. Yerkes

High Technology Center

Post Office Box 3999, MS 7J-71

Seattle, WA 98124-2499

Boeing Electronics Company

Attn: Dr. Lewis Fraas

P. O. Box 24969, MS 9Z-80

Seattle, WA 98124-6269

Mr. Clement Chiang

GE Astrospace, MS NP-2K

100 Nassau Park Boulevard

West Windsor, NJ 08543-800

Crystal Systems

Attn: Fred Schmid

27 Congress Street

Salem, MA 01970
ENTECH

Attn: Mark O'Neill

P. 0. Box 612246

DFW Airport, TX 75261

EPRI (3)

Attn: Frank Dostalek

John Bigger

Frank Goodman

P. 0. Box 10412

Palo Alto, CA 94303

Georgia Institute of

Technology

School of Electrical Engr.

Attn: Professor Ajeet Rohatgi

Atlanta, GA 30331

James Associates

Attn: Larry James

7329 Meadow Court

Boulder, CO 80301

Jet Propulsion Lab (2)

Attn: Russ Sugimura

Ron Ross

4800 Oak Grove Drive

Pasadena, CA 91109

Kopin

Attn: Ron Gale

695 Myles Standish Blvd.

Taunton, MA 02780

Midway Labs

Attn: Paul Collard

2255 East 75th Street

Chicago, IL 60649

Mobil Solar Energy Corp.

Attn: Juris Kalejs

Four Suburban Park Drive

Billerica, MA 01821

NASA/Lewis Research Center (2).

Attn: Shiela Bailey

Dennis Flood

MS 302-1

21000 Brookpark Road

Cleveland, OH 44135 
NREL (5)

Attn: Dick DeBlasio

Laxmi Mrig

Bhushan Sopori

Ted Ciszek

John Benner

1617 Cole Boulevard

Golden, CO 80401

NREL Library

1617 Cole Boulevard

Golden, CO 80401

Photonic Power Systems, Inc.

Attn: Jan Werthan

550 California Avenue

Palo Alto, CA 94306

Purdue University (2)

Attn: Dick Schwartz

Jeff Gray

School of Electrical Engr.

West Lafayette, IN 47907

Siemens Solar, Inc.

Attn: Kim Mitchell

Post Office Box 6032

Camarillo, CA 93011

Solar Engineering Applications

Attn: Neil Kaminar

305 North Mathilda Avenue

Sunnyvale, CA 94086

Solar Kinetics, Inc.

Attn: Shabbar Saifee

P. O. Box 540636

Dallas, TX 75354-0636

Solarex Corporation

Attn: John Wohlgemuth

630 Solarex Court

Frederick, MD 20701

Southern California Edison

Attn: Nick Patapoff

6090 Irwindale Avenue

Irwindale, CA 91702

Spectrolab (2)

Attn: Dmitri Krut

James Albeck

12500 Gladstone Avenue

Sylmar, CA 91342
Spire Corporation

Attn: Michael J. Nowlan

Patriots Park

Bedford, MA 01730

SunPower Corp.

Attn: Richard Swanson

435 Indio Way

Suite 100

Sunnyvale, CA 94086

Texas Instruments

Attn: Jules Levine

Post office Box 655012

Dallas, TX 75265

US Department of Energy

Attn: James Rannels, CE-131

Forrestal Building

1000 Independence Avenue, SW

Washington, DC 20585

Wattsun

Attn: John Doherty

Post Office Box 751

Albuquerque, NM 87103

University of New South Wales

Attn: Dr. Martin Green

School of Electrical Engr.

Post Office Box One

Kensington, NSW 2033

AUSTRALIA

Fraunhofer Institute for Solar

Energie Systeme

Attn: Klaus Heidler

Oltmannsstrasse 22

D-7800 Freiburg

GERMANY

Instituto de Energia Solar

Ciudad Universitaria, $s / n$

Attn: Antonio Luque

ETSI Telecomunicacion (UPM)

28040 Madrid

SPAIN

6200 B. W. Marshall

6202 G. J. Jones

6213 T. C. Bickel

6213 P. A. Basore

6213 T. D. Hund

6213 A. B. Maish

$6213 \mathrm{~J} . \mathrm{R}$. Woodworth

6213 J. M. Gee

6213 D. S. Ruby 
6213 W. K. Schubert

6218 D. E. Hasti

6219 M. L. Whipple

6219 D. L. King

7141 Technical Library (5)

7151 Tech. Publications (1)

7613-2 Document Processing DOE/OSTI (10)

8523-2 Central Tech. Files (1) 